\title{
Age and Sex Differences in Mitotic Activity within the Zebra Finch Telencephalon
}

\author{
Valerie DeWulf and Sarah W. Bottjer \\ Program in Neuroscience, University of Southern California, Los Angeles, California 90089-2520
}

\begin{abstract}
Brain regions associated with song learning in zebra finches are larger and contain more neurons in males than females. Differences in cell proliferation, migration, survival, and specification may all contribute to the divergent development of the songcontrol system in developing birds. This study quantified levels of cell proliferation within the telencephalic ventricular zone (VZ) of juvenile and adult birds to look for both age and sex differences in mitotic activity that might contribute to the construction of song-control circuits. A single pulse of $\left[{ }^{3} \mathrm{H}\right]$ thymidine was administered to juveniles and adults of both sexes, and animals were killed 2 hr later. Analysis of thymidine labeling within the telencephalic VZ at the levels of area X, the anterior commissure, and high vocal center (HVC) revealed two major findings: (1) levels of mitotic activity decreased as a function of age in both males and females because of a reduction in the
\end{abstract}

Young male zebra finches learn to sing a close copy of their father's song during a sensitive period of development from $\sim 20$ to $90 \mathrm{~d}$ after hatching (Böhner, 1990), whereas young females never learn to produce song behavior. The neural substrate underlying bird song, the song-control system, is highly sexually dimorphic (Nottebohm and Arnold, 1976; Nottebohm et al., 1982; Bottjer et al., 1989). However, it is difficult to determine whether neural sex differences are the result of sexually dimorphic proliferation, migration, differentiation, or cell death (for review, see Alvarez-Buylla and Kirn, 1997).

Neuroblasts originate in the proliferative ventricular zone (VZ) adjacent to the lateral ventricles (Goldman and Nottebohm, 1983; Alvarez-Buylla et al., 1988, 1990), migrate into the brain along radial glial processes, and become incorporated into various regions of the telencephalon (Alvarez-Buylla and Nottebohm, 1988). A larger number of new neurons are incorporated into high vocal center (HVC) and area $\mathrm{X}$ of young males compared with young females (Bottjer et al., 1986; E. J. Nordeen and K. W. Nordeen, 1988; K. W. Nordeen and E. J. Nordeen, 1988; AlvarezBuylla et al., 1992). The incidence of pyknotic cells within HVC is greater in females than males before $20 \mathrm{~d}$ of age but may be equivalent thereafter (Kirn and DeVoogd, 1989; Burek et al.,

\footnotetext{
Received June 28, 2001; revised Jan. 8, 2002; accepted Jan. 23, 2002.

This work was supported by National Institutes of Health Grant DC-02715. We thank Alicia Thompson for excellent technical assistance, Jason Zevin for programming assistance, Dr. David Lavond for advice on statistical analysis, and Dr. Ed Rubel for expert advice on overall experimental design.

Correspondence should be addressed to Sarah W. Bottjer, USC, HNB 218, 3641 Watt Way, Los Angeles, CA 90089-2520. E-mail: bottjer@usc.edu.

V. D. DeWulf's present address: House Ear Institute, Cell and Molecular Biology, 2100 West Third Street, Los Angeles, CA 90057.

Copyright (C) 2002 Society for Neuroscience $\quad 0270-6474 / 02 / 224080-15 \$ 15.00 / 0$
}

number of dividing cells within the VZ, and (2) sex differences in thymidine labeling occurred in restricted, localized segments of the $\mathrm{VZ}$ at the levels of area $\mathrm{X}$ and the anterior commissure in juveniles but not adults. Thus, overall proliferative activity decreases as birds mature, and the incidence of cell division in all regions of the $\mathrm{VZ}$ becomes equivalent in both sexes, such that no regions of sexually dimorphic proliferation are evident by adulthood. These data suggest that regions of sexually dimorphic proliferation within the VZ may contain precursor cells that give rise to song-control neurons, such that higher rates of mitotic activity in juvenile males could contribute to the growth of songcontrol nuclei such as HVC and area X.

Key words: neurogenesis; stem cell; proliferation; songbird; vocal learning; ventricular zone (VZ)

1994, 1997). Burek et al. (1994) also demonstrated that a sex difference in the number of new HVC neurons within a timed cohort of cells is evident several days after birth, before all cells in the cohort finish their migration and differentiation. Together, these experiments suggest that differences in cell specification and survival contribute to the development of the song-control system. However, no studies have detected sex differences in proliferative activity within the VZ, which would constitute initial evidence for a direct contribution of cell proliferation to sexually dimorphic neural circuitry.

The present experiment directly tested whether the telencephalic VZ of zebra finches contains higher levels of proliferation in juveniles compared with adults and in males compared with females. We administered a single pulse of $\left[{ }^{3} \mathrm{H}\right]$ thymidine to juvenile ( $30 \mathrm{~d})$ and adult $(>90 \mathrm{~d})$ birds of both sexes and killed the animals 2 hr later to examine proliferative activity uncontaminated by cell death or migration away from the VZ. Increased levels of thymidine labeling were evident at the levels of area $\mathrm{X}$, the anterior commissure, and HVC in juveniles relative to adults, and single-cell analysis indicated that higher levels of mitotic activity were attributable to a larger number of dividing cells in the VZ. In addition, restricted regions of sexually dimorphic cell division were observed at the levels of area $\mathrm{X}$ and the anterior commissure in which cell proliferation was greater in juvenile males than juvenile females. No regions of the VZ demonstrated sex differences in thymidine labeling in adults. These observations suggest that sex differences in cell proliferation may contribute to the growth of song-control nuclei in males. Moreover, regions of sexually dimorphic proliferation within the $\mathrm{VZ}$ may offer clues to the location of the precursor cells that give rise to song-control neurons. 


\section{MATERIALS AND METHODS}

Thymidine labeling and tissue preparation. Twenty-eight male and female zebra finches were taken from our breeding colony at either $30 \mathrm{~d}$ of age (juveniles; range, 28-32 d) or $\geq 90 \mathrm{~d}$ of age (adults) to measure levels of mitotic activity adjacent to the lateral ventricles within the telencephalon. Each bird received a single intramuscular injection of $\left[{ }^{3} \mathrm{H}\right]$ thymidine [2.5 $\mu \mathrm{Ci} / \mathrm{gm}$ dose; specific activity, $6.7 \mathrm{Ci} / \mathrm{mmol}$; New England Nuclear (Boston, MA) or ICN (Cleveland, $\mathrm{OH}$ )] and was killed $2 \mathrm{hr}$ later. This post-thymidine interval is short enough to effectively preclude loss of cells attributable to cell death or migration away from the VZ, both of which would produce specious estimates of actual proliferative activity. Age-related changes in the duration of S phase might also influence the rate of thymidine incorporation (i.e., less DNA would be labeled during the time that $\left[{ }^{3} \mathrm{H}\right]$ thymidine is available for longer $\mathrm{S}$ phases), but the length of $\mathrm{S}$ phase has been shown to remain constant over development despite large increases in the total length of the cell cycle (Caviness et al., 1995; Takahashi et al., 1995). Therefore, the incidence of thymidine labeling should provide an uncontaminated estimate of developmental changes in proliferative activity.

All birds were overdosed with a barbiturate anesthetic (Equithesin) and transcardially perfused with avian saline followed by $2 \%$ paraformaldehyde $-2 \%$ glutaraldehyde fixative. Brains were removed and bisected along the midline into two hemispheres for embedding (the left hemisphere in paraffin and the right hemisphere in the water-soluble plastic LR White; Ted Pella, Redding, CA). Before embedding, each hemisphere was post-fixed in either buffered formalin (left hemisphere) or $2 \%$ paraformaldehyde-2\% glutaraldehyde (right hemisphere) for several days. To compensate for possible variation across sex and age groups (e.g., emulsion batches, lots of $\left[{ }^{3} \mathrm{H}\right]$ thymidine), all procedures included at least one animal from each of the four groups for both the paraffin- and the plastic-embedded brains.

Paraffin-embedded hemispheres. Paraffin sections were used to measure overall levels of proliferation adjacent to the lateral ventricles at three different levels of the brain: area X, the anterior commissure, and HVC in juveniles (males, $n=5$; females, $n=6$ ) and adults (males, $n=5$; females, $n=5$ ) (Fig. 1). Briefly, coronal sections were cut on a rotary microtome at a thickness of $10 \mu \mathrm{m}$, placed on chrome-alum-subbed slides, and immersed in a series of xylenes and graded alcohols for paraffin removal. The slides were then dipped in nuclear track emulsion (Kodak NTB2; Eastman Kodak Co., Rochester, NY), stored at $4^{\circ} \mathrm{C}$ for 3-8 weeks, developed (Kodak D19), and counterstained with thionin.

Plastic-embedded hemispheres. Observation of tissue sections in pilot studies had revealed that the density of cells within the VZ was extremely high, making it impossible to visualize individual cells even in 5-6 $\mu \mathrm{m}$ tissue sections. Therefore, to analyze thymidine labeling within single cells, we cut serial $1 \mu \mathrm{m}$ sections from plastic-embedded hemibrains at the level of the anterior commissure (juvenile males, $n=8$; juvenile females, $n=8$; adult males, $n=7$; adult females, $n=5$ ). We trimmed $\sim 2$ $\mathrm{mm}$ of the lateral lobe of the telencephalon; the remaining tissue was then bisected into anterior and posterior halves at the optic tectum, and each brain quarter was embedded in separate capsules. Plastic-embedded sections were cut in the coronal plane on a JB-4 retracting rotary microtome (EBS Inc., Agawana, MA) and processed for tissue autoradiography by the same methods used for the paraffin-embedded tissue. The number of hemibrains embedded in plastic versus paraffin differed because originally several right hemibrains were trimmed incorrectly and the dorsolateral portion of the lateral ventricle was inadvertently removed. To increase the number of brains with intact lateral ventricles for complete single-cell analysis, additional birds were processed and the right hemispheres were embedded in plastic.

\section{Analysis of autoradiograms}

Proliferative zones of the zebra finch telencephalon. All analyses of cell proliferation were performed using a computer-aided imaging system (Analytical Imaging Concepts, Roswell, GA) yoked to a microscope. Observation of thymidine-labeled cells adjacent to the lateral ventricles revealed three different proliferative zones within the zebra finch telencephalon (Fig. 1). The proliferative epithelium described here is what has classically been referred to as the VZ in mammalian brain and consists of an epithelial cell layer adjacent to the lateral ventricles (Boulder Committee, 1970). Immediately adjacent to the ventral VZ (VVZ) (within the striatum), a population of small, round, closely packed cells tended to include a large number of silver grains. This subventricular zone (SVZ) appeared to be morphologically identical to the SVZ described within the developing mammalian brain (Boulder Committee, 1970). The SVZ was only apparent ventral to the dorsal medullary lamina (LMD fiber tract, which separates striatum from overlying cortex) at the levels of area $X$ and the anterior commissure (Fig. 1a,b), and the SVZ was never observed at the level of HVC (at this caudal level of the telencephalon, the striatum and VVZ are gone). In addition to the VZ and SVZ, groups of thymidine-labeled cells were seen adjacent to the VZ and SVZ in the brain parenchyma. These accumulations of thymidine-labeled cells extended up to $185 \mu \mathrm{m}$ lateral to the $\mathrm{VZ}$, were more abundant within striatum than cortex, and were not associated with blood vessels. Thymidine-labeled cells in the brain parenchyma were excluded from analysis if they were $>185 \mu \mathrm{m}$ from the VZ or if they were clearly endothelial cells associated with blood vessels.

Paraffin-embedded brains. The exact location of the precursor cells that produce song-control neurons is unknown. For this reason, we decided to measure levels of proliferation at two levels of the telencephalon that include song-control regions, area $\mathrm{X}$ and $\mathrm{HVC}$, and at one level of the brain not containing song control nuclei, the anterior commissure. To ensure that equivalent locations of the $\mathrm{VZ}$ were traced, sections taken from the same anterior-posterior level of the telencephalon, based on their distance from the anterior commissure, were used to measure proliferation at area X and HVC of juveniles and adults of both sexes. The anterior commissure was obvious in all animals; thus only sections that contained the anterior commissure were used to measure proliferation at this level of the telencephalon. We ensured that all tissue was cut at the same angle by only analyzing brains in which specific nuclei in the telencephalon (dorsally) and tectum (ventrally) were present in individual sections at the levels of both the anterior commissure and HVC.

Although we could not discern individual VZ cells within the paraffinsectioned tissue (see above), we could unambiguously count the total number of silver grains in these sections. Thus, we used the $10 \mu \mathrm{m}$ sections to measure total, overall levels of mitotic activity in each proliferative zone (VZ, SVZ, and within the brain parenchyma adjacent to the VZ and SVZ). To estimate the total amount of proliferation within the VZ, the perimeter of the entire dorsal-ventral extent of the VZ was outlined in three tissue sections $100-150 \mu \mathrm{m}$ apart at each level of the brain analyzed (Fig. 1a-c, dark gray area). The average area of the VZ and the total number of silver grains therein were measured at each brain level; the number of silver grains was then divided by area to calculate the silver-grain density. To measure total proliferative activity within the SVZ, the perimeter of the SVZ was outlined where it occurred along the VVZ at the levels of area $\mathrm{X}$ and the anterior commissure (Fig. 1a,b). The area of the SVZ, total number of silver grains, and density of silver grains were measured at each of these brain levels as for the VZ. The overall level of mitotic activity within the proliferative zone adjacent to the $\mathrm{VZ}$ was measured by outlining aggregations of labeled cells and counting the total number of silver grains within each aggregate in the brain parenchyma up to $185 \mu \mathrm{m}$ from the VZ. The total number of silver grains is the only parameter presented for thymidine labeling adjacent to the $\mathrm{VZ}$ within the brain parenchyma because these thymidine-labeled clusters of cells were not confined to a specific delimited region; thus it was impossible to determine the area of this proliferative zone.

To ensure that our measurements accurately reflected thymidine incorporation into dividing cells distinct from background labeling, the density of silver grains within a large region of brain parenchyma $\left(\sim 14,000 \mu \mathrm{m}^{2}\right)>200 \mu \mathrm{m}$ away from the $\mathrm{VZ}$ was measured for each section analyzed, excluding any labeled glial or endothelial cells. This background measure of thymidine labeling was used to estimate the total number of silver grains that would be expected in a given traced area. The expected number of silver grains was then subtracted from the raw silver-grain counts in the VZ, SVZ, and proliferation adjacent to the VZ. Because the total number of silver grains is a direct measure of thymidine uptake (and thus an estimate of total mitotic activity), this procedure enabled us to determine the overall incidence of cell division within each proliferative zone above and beyond background thymidine labeling. We compared background levels of thymidine labeling among groups to evaluate whether thymidine was equally available in juvenile and adult brains. There was no difference in the background silver-grain density between juvenile or adult males and females, indicating that the availability of thymidine was equivalent among groups.

Plastic-embedded brains. Our analysis of proliferative activity in the 10 $\mu \mathrm{m}$ sections demonstrated a robust age difference (mitotic activity was much higher throughout the telencephalon in juveniles than in adults; see below). To determine the cell parameters underlying this developmental decrease in mitotic activity, we quantified total cell number (both unlabeled and labeled) and cellular area in individual cells within subregions 
Figure 1. Schematic coronal sections through the zebra finch brain at the levels of area $\mathrm{X}(a)$, the anterior commissure $(b)$, and HVC (c). A, Anterior; $D$, dorsal; $L$, lateral; $M$, medial; $P$, posterior, $V$, ventral. Proliferation in the telencephalon occurs in the epithelium adjacent to the lateral ventricle, the VZ (black arrows), and the SVZ (gray arrows). Asterisks indicate the locations of thymidine-labeled cell clusters in the brain parenchyma. $d$, A separate cross section of the telencephalon indicating the boxed regions measured in the $1 \mu \mathrm{m}$ plastic tissue analysis. $e$, Photomicrograph of the $\mathrm{VZ}$ in a $1-\mu \mathrm{m}$-thick section demonstrating the out-pocketing of the VZ in juvenile birds. $C x$, Cortex; Str, striatum; $C b$, cerebellum; $V$, lateral ventricle; $L A D$, lamina archistriatalis dorsalis; $A C$, anterior commissure; $L H$, lamina hyperstriatica; $L M D$, lamina medullaris dorsalis.

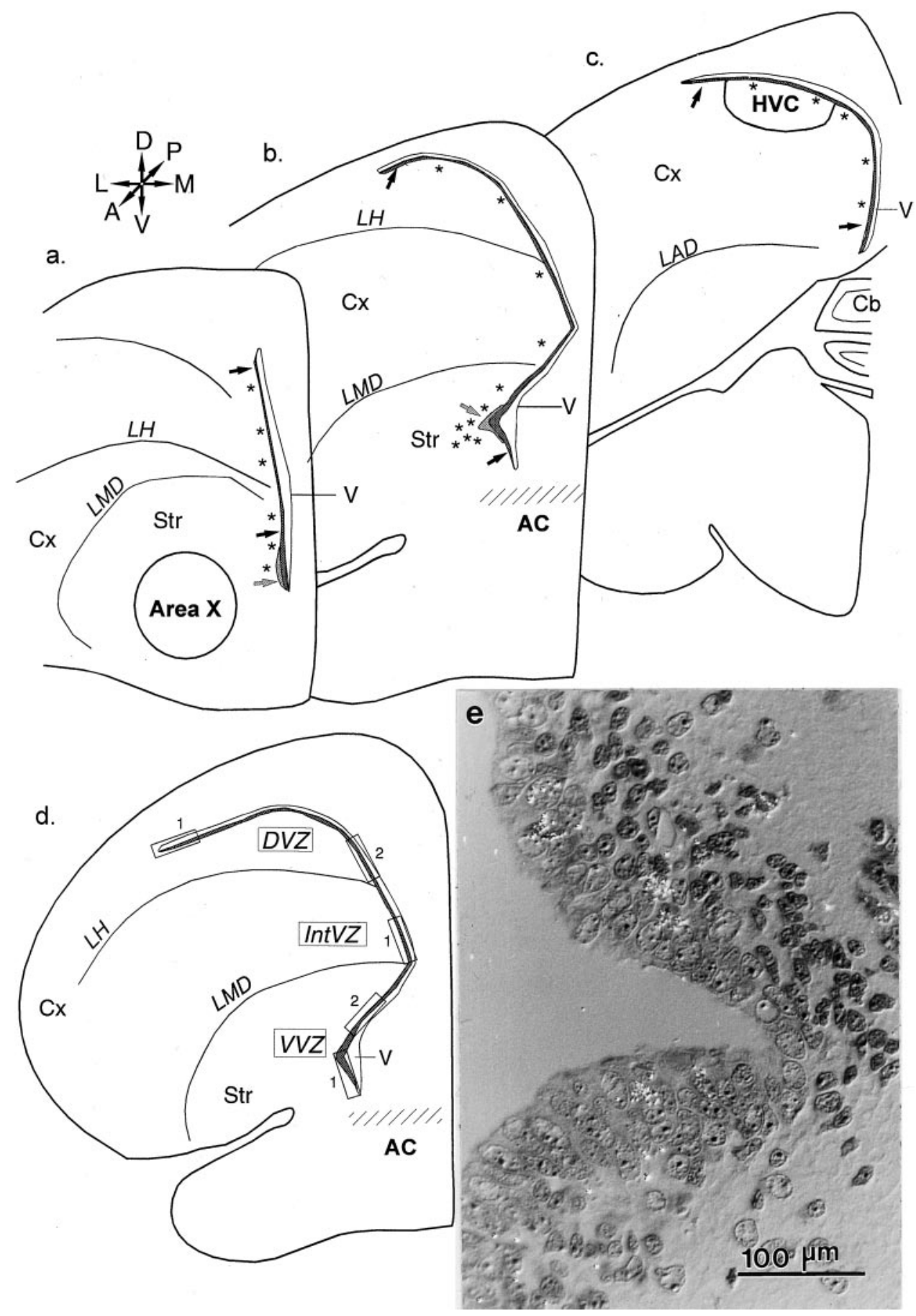

of the VZ at the level of the anterior commissure in $1 \mu \mathrm{m}$ sections. These data provided quantitative estimates of the total number of cells as well as the proportion and density of thymidine-labeled cells in different subregions of the VZ. To see whether counts of single cells corresponded well to our estimates of total mitotic activity based on counting the total number of silver grains, we also measured the area and total number and density of silver grains within the same subregions of the VZ in which we analyzed single cells.

For this analysis, three tissue sections within a $100 \mu \mathrm{m}$ interval were analyzed for each bird. The VZ within each section was divided into three different subregions (Fig. 1d): (1) the VVZ was defined as the proliferative epithelium extending from the ventral tip of the $\mathrm{VZ}$ to the LMD fiber tract; (2) an intermediate region of the VZ (IntVZ) was situated between the LMD and hyperstriatal lamina (LH) fiber tracts; and (3) the dorsal VZ (DVZ) extended from the LH fiber tract to the dorsal tip of the VZ. Within each of these subregions, segments of the VZ corresponding to the boxed areas shown in Figure $1 d$ were sampled as follows: for each boxed segment, we traced the area of the $\mathrm{VZ}$ along a linear length of $165 \mu \mathrm{m}$ (corresponding to three alternating $55 \mu \mathrm{m}$ segments). We measured two different segments of the VZ within both the DVZ and VVZ (e.g., VVZ1 and VVZ2) and one segment of the VZ within the IntVZ (Fig. 1d). To measure numbers of labeled and unlabeled cells within these segments of the VZ, the perimeter of each individual cell was outlined and the total number of silver grains present within each cell was counted. Criteria for tracing cells included the presence of a limiting membrane and some well stained chromatin within the cell profile. The intensity of thymidine labeling (number of times background) was calculated for each cell, and individual cells were scored as labeled if the density of silver grains over them exceeded ten times the density of silver grains over background. We also counted the 
total number of silver grains within each segment (silver-grain counts were corrected by subtracting levels of background labeling from the raw silver-grain counts, as described above). The measures of area and total number of silver grains represent estimates of total proliferative activity within each segment, which are comparable with our previous estimates of overall thymidine labeling made in $10 \mu \mathrm{m}$ sections.

\section{Mapping proliferation within the $V Z$}

Our single-cell analysis revealed a sex difference in a small segment of the VZ in juvenile but not adult zebra finches (see below). This serendipitous discovery raised the question of how extensive such sexually dimorphic mitotic activity might be. In addition, the level of proliferative activity within the VZ was highly spatially differentiated in both juvenile and adult brains. For example, qualitative observation at the level of the anterior commissure indicated that levels of proliferation were highest in the ventral portion of the VZ within the striatum, raising the question of how great a quantitative difference would exist between levels of proliferation in cortex versus striatum. As a first step in exploring these questions, we decided to map the incidence of thymidine labeling in progressive segments along the DVZ and VVZ at the levels of the anterior commissure and area $\mathrm{X}$ in both juvenile and adult birds. We did not include the level of HVC, because the VVZ is gone by this level.

Mapping proliferation in the $V Z$ at the levels of area $X$ and the anterior commissure. The $10 \mu \mathrm{m}$ paraffin tissue sections generated for our original measurements of total proliferation were used to measure the incidence of mitotic activity along the DVZ and VVZ (separately) in juvenile and adult zebra finches of both sexes. To measure the incidence of mitotic activity in progressive segments along the DVZ, the total linear length of the DVZ (i.e., from the LH fiber tract to the dorsal tip of the VZ, see above and Fig. 1) was calculated and divided by 10 . The resulting bins represent the incidence of proliferation in $10 \%$ increments along the length of the DVZ, thereby allowing us to compare levels of mitotic activity for corresponding locations within the DVZ among animals. The area, total number of silver grains, and silver-grain density within each bin were calculated. The same approach was used to measure the spatial distribution of thymidine labeling within the VVZ from the ventral tip of the VZ to the LMD fiber tract. Background measurements of silver-grain density were made and used to adjust silver-grain counts to exclude background labeling within the DVZ and VVZ as described above for the $10 \mu \mathrm{m}$ tissue analysis. In this way, we were able to accurately map levels of proliferation in $10 \%$ intervals along the entire length of the DVZ and VVZ separately at the level of both area X and the anterior commissure.

All statistical comparisons were made using $2 \times 2$ ANOVAs with age and sex as between-group factors in our 10 and $1 \mu \mathrm{m}$ tissue analyses and bins as a within-group factor in our mapping study. Student's $t$ tests were used to compare individual group differences. All tests were considered significant if they exceeded the 95\% confidence level (two-tailed).

\section{RESULTS}

\section{Overall pattern of thymidine labeling in the brain: qualitative observations}

Brain and body weights of zebra finches are at their adult levels by 25-30 d of age; therefore, we had conceived this study with the idea that cell division in the telencephalic neuroepithelium of 30-d-old zebra finches would likely have achieved adult (i.e., decreased) levels. If so, then we might be able to see isolated pockets of upregulated mitotic activity within the $\mathrm{VZ}$ in close proximity to the song-control nuclei HVC and area X of juvenile males. Both these regions grow substantially in overall volume through neuron addition during song learning in juvenile males after other, nonsong regions are fully developed (Bottjer et al., 1986; Herrmann and Bischof, 1986; K. W. Nordeen and E. J. Nordeen, 1988). Such pockets of increased mitotic activity might therefore contain the progenitor cells that produce song-control neurons destined for area $\mathrm{X}$ and HVC. However, qualitative examination of cell proliferation revealed a larger $\mathrm{VZ}$ with a higher incidence of thymidine labeling throughout the telencephalon of juvenile birds compared with adults. Although juveniles had higher levels of mitotic activity than did adults, overall levels of proliferation appeared to be equivalent among males and females at each age, and no broad regions of increased proliferative activity were obvious in relation to $\mathrm{HVC}$ or area $\mathrm{X}$ in juveniles or adults of either sex. Proliferative activity at both ages was restricted to the telencephalon, such that no labeled cells were evident in the diencephalon or below (Alvarez-Buylla et al., 1990, 1994; Ling et al., 1997).

Mitotic activity within the telencephalon was localized to three distinct proliferative zones in juvenile and adult zebra finches of both sexes: the VZ, the SVZ, and scattered pockets of thymidine labeling adjacent to the VZ and SVZ in the brain parenchyma (Fig. 1; see Materials and Methods). The SVZ that we observed in the zebra finch telencephalon was localized to the striatum (adjacent to the VVZ) in both juveniles and adults, as is true in adult mammals (Garcia-Verdugo et al., 1998). Of the three proliferative zones that we observed, only the VZ and SVZ have been described in the developing mammalian brain (Boulder Committee, 1970). In addition, other studies of cell proliferation in avian brain using short survival times after thymidine exposure have not described aggregations of labeled cells outside of the VZ and SVZ (Alvarez-Buylla et al., 1990; Ling et al., 1997). The short ( $2 \mathrm{hr}$ ) survival interval after thymidine exposure used in our study seems to rule out the possibility that this group of labeled cells had migrated out from the VZ or SVZ. These labeled cells in the brain parenchyma have morphological characteristics similar to those of thymidine-labeled cells within the VZ and SVZ and hence might represent a population of stem cells situated close to the VZ. An alternative possibility is that this zone of proliferation represents a population of cells dividing while en route to their final destination.

Although the increased level of mitotic activity seen in juvenile brains was quite ubiquitous along the rostrocaudal axis of the telencephalon, the pattern of labeling was not uniform in either juveniles or adults. The relative thickness of the VZ and SVZ, as well as the incidence of thymidine labeling, varied depending on the dorsal-ventral and anterior-posterior location along the neuraxis. For example, each proliferative zone was thickest along the ventral aspect of the lateral ventricles within medial striatum of the avian basal ganglia (parolfactory lobe) at the level of the anterior commissure (Fig. 1) in both juveniles and adults. This region of thicker $\mathrm{VZ}$ along the ventral lateral ventricles always included relatively high numbers of silver grains, such that the highest levels of mitotic activity in the telencephalon occurred here. High levels of thymidine labeling were localized not only to this "hot spot" near the ventral horn of the lateral ventricles at the level of the anterior commissure but also to a smaller aggregation of thymidine labeling around the dorsal horn (Alvarez-Buylla et al., 1990). Within the ventral area of increased labeling, we observed a distinct out-pocketing of the proliferative epithelium in juvenile brains (Fig. 1b,e). This region of the VZ always included a very distinct bulge in juvenile brains, whereas adult brains tended to have a much less pronounced, shallow inclination in the VZ (Fig. 2). In addition, this out-pocketing in the proliferative epithelium was significantly larger and appeared to be more proliferatively active in juveniles than in adults.

The thickness of the VZ and incidence of silver grains also tended to be slightly higher within the ventral aspect of the VZ more rostrally, at the level of area $\mathrm{X}$, but this tendency was much less pronounced than at the anterior commissure (Fig. 1). In addition, the SVZ was much less obvious at this level, particularly in adult brains. The SVZ tended to colocalize with thicker portions of the $\mathrm{VZ}$ along the ventral aspect of the lateral ventricles in 
Figure 2. Autoradiograms showing thymidine labeling within the ventral portion of the VZ at the level of the anterior commissure in a juvenile male $(a)$ and an adult female $(b)$. Thymidine labeling in the SVZ (arrowheads) and clusters of thymidinelabeled cells (arrows) adjacent to the VZ are apparent. A large out-pocketing in the $\mathrm{VZ}$ is apparent in juveniles, whereas the out-pocketing is much reduced in adults. $V$, Lateral ventricle.
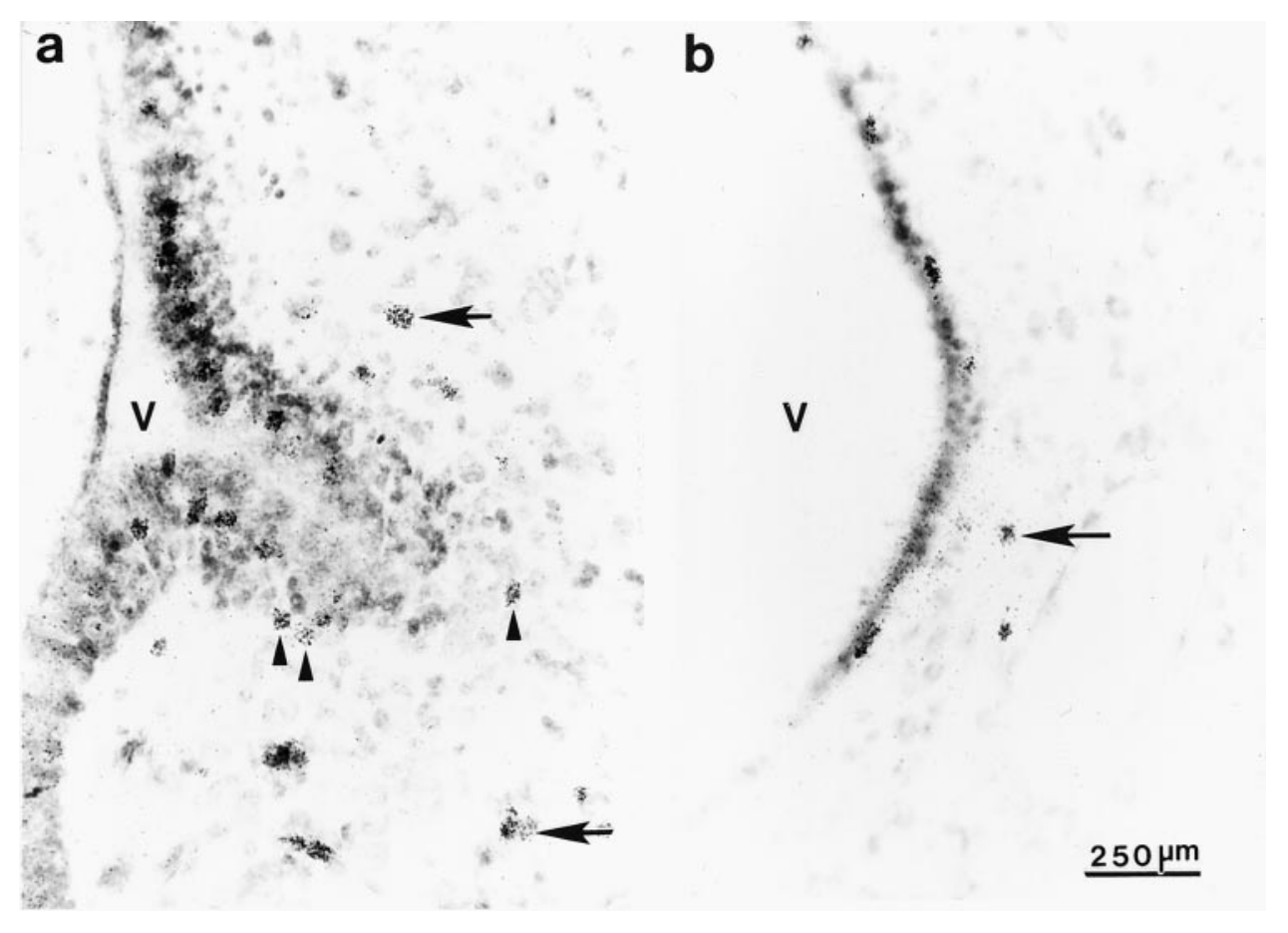

both juvenile and adult brains and was first clearly recognizable adjacent to the VVZ midway through the rostral-caudal extent of area $\mathrm{X}$ in juveniles. In adults, the SVZ was not apparent until the caudalmost level of area X. A spatially differentiated pattern of proliferation was much less evident in the caudal telencephalon, at the level of HVC, by which point the basal ganglia are gone. The SVZ was not apparent in either juvenile or adult brains at the level of HVC. In summary, a spatially differentiated pattern of labeling was evident in the telencephalon of both juveniles and adults, despite the higher incidence of proliferative activity in juveniles than in adults.

\section{Quantitative observations in $10 \mu \mathrm{m}$ sections}

Area $X$

Quantitative analysis at the level of area $X$ confirmed that the overall area of the $\mathrm{VZ}$ was larger in juveniles than in adults $\left(F_{(1,15)}=19.22 ; p=0.0005\right)$ (Fig. $3 a$ ) but did not differ between males and females at either age (main effect of sex: $F<1$ ). The total proliferative activity within the $\mathrm{VZ}$ at the level of area $\mathrm{X}$ was also significantly greater in juveniles than in adults, as indicated by a greater total number of silver grains $\left(F_{(1,15)}=12.66 ; p=\right.$ 0.003 ) (Fig. $3 b)$, but there was no sex difference in number of silver grains within juveniles or adults (main effect: $F_{(1,15)}=1.15$; $p=0.3$ ). The age difference in mitotic activity was robust: the total number of silver grains was more than five times higher in juveniles than adults at this level of the brain. This greatly increased number of silver grains in juvenile birds contributed to a significantly greater density of silver grains within this portion of the VZ in juveniles compared with adults $\left(F_{(1,15)}=13.60 ; p=\right.$ $0.002)$, but silver-grain density did not differ between males and females $\left(F_{(1,15)}=2.07 ; p=0.17\right.$ ) (Fig. $\left.3 c\right)$.

We did not quantify the incidence of labeling within the SVZ at area $\mathrm{X}$, because this proliferative zone was not consistently represented at this level of the brain (see above). Only 3 of 9 adult brains had a clearly visible region of $\mathrm{SVZ}$ adjacent to the $\mathrm{VVZ}$ at area $\mathrm{X}$, whereas 7 of 10 juveniles had an observable SVZ. Both juvenile and adult brains did have clusters of thymidine labeling adjacent to the $\mathrm{VZ}$ at area $\mathrm{X}$. The total number of silver grains observed in these clusters within the brain parenchyma was significantly greater in juveniles than in adults $\left(F_{(1,14)}=11.96\right.$; $p=0.004$ ) (Fig. $4 d$ ), but mitotic activity did not differ between males and females $(F<1)$.

\section{Anterior commissure}

The pattern of proliferation at the level of the anterior commissure was similar to that observed at area $X$ in that the area of the $\mathrm{VZ}$ was larger in juveniles than in adults $\left(F_{(1,16)}=25.36 ; p=\right.$ $0.0001)$ (Fig. 3) and did not differ as a function of $\operatorname{sex}(F<1)$. Overall levels of proliferation were also significantly higher in juveniles than adults, as indicated by the total number of silver grains $\left(F_{(1,16)}=13.12 ; p=0.002\right)$. However, the density of silver grains did not differ between juveniles and adults $\left(F_{(1,16)}=1.22\right.$; $p=0.29)$, because the relative age difference for both $\mathrm{VZ}$ area and total number of silver grains was roughly comparable (Fig. 3, compare $a$ and $b$ ). There was no sex difference at either age in the total number of silver grains or the silver-grain density within the VZ (both $F<1$ ).

The SVZ was also larger and more proliferatively active in juveniles than adults at the level of the anterior commissure. Area measurements of the SVZ demonstrated that this proliferative zone was approximately four times larger in juvenile males and females than adults at this level of the brain $\left(F_{(1,18)}=19.56 ; p=\right.$ 0.0003; $F<1$ for main effect of sex) (Fig. $4 a$ ). The total number of silver grains within the SVZ was higher in juveniles than adults but did not differ as a function of $\operatorname{sex}\left(F_{(1,18)}=9.28 ; p=0.007\right.$; main effect of sex: $\left.F_{(1,18)}=1.84 ; p=0.19\right)$ (Fig. 4b). The silver-grain density within the SVZ did not vary as a function of age $\left(F_{(1,18)}=1.23 ; p=0.28\right)$ or $\operatorname{sex}(F<1)$ (Fig. $\left.4 c\right)$. The number of silver grains in the brain parenchyma adjacent to the $\mathrm{VZ}$ at the level of the anterior commissure was approximately twice as high in juveniles as in adults $\left(F_{(1,18)}=19.87 ; p=0.0003\right)$ (Fig. $\left.4 d\right)$, and there was no sex difference in thymidine labeling adjacent to the $\mathrm{VZ}(F<1)$. 

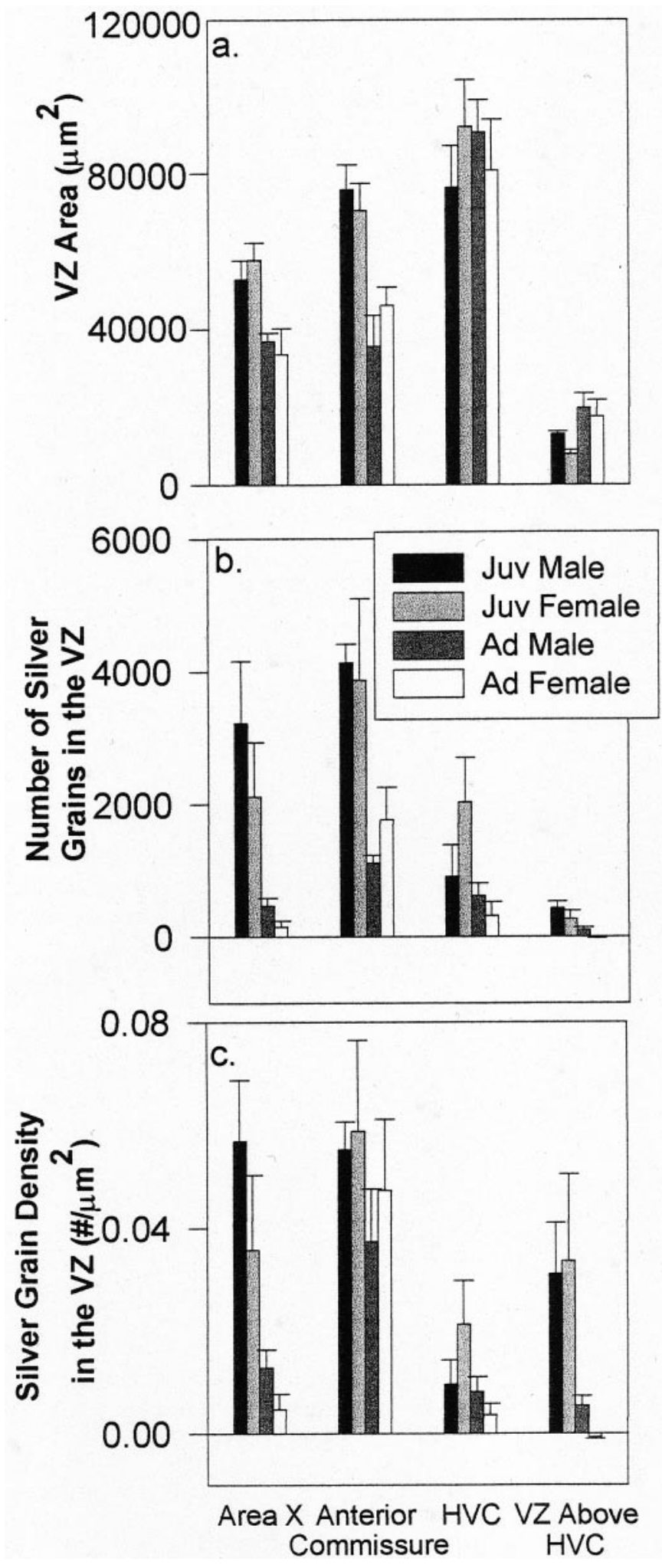

Figure 3. A $10 \mu \mathrm{m}$ tissue analysis demonstrating the area of the $\operatorname{VZ}(a)$, the total number of silver grains $(b)$, and silver-grain density within the $\mathrm{VZ}(c)$ at the levels of area X, the anterior commissure, HVC, and the VZ immediately above HVC in juveniles (Juv) and adults $(A d)$ of both sexes (mean \pm SEM).
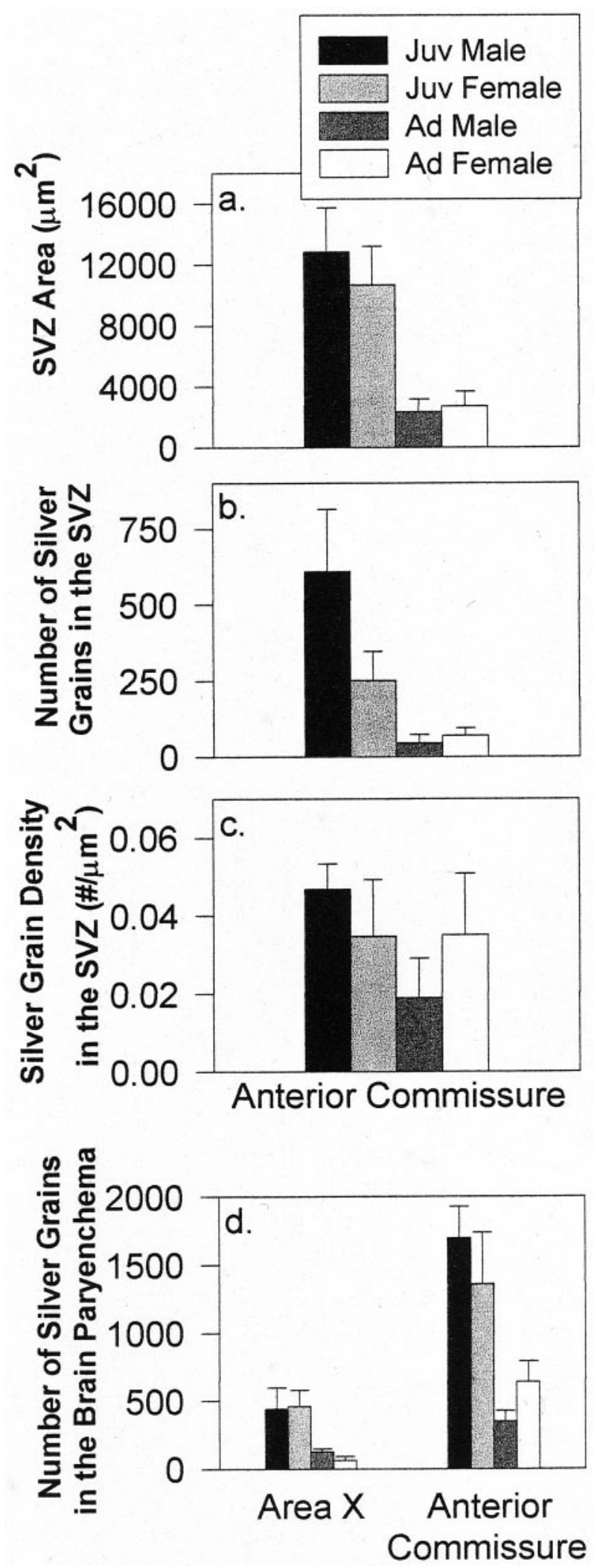

Figure 4. A $10 \mu \mathrm{m}$ tissue analysis demonstrating the area of the $\operatorname{SVZ}(a)$, the total number of silver grains $(b)$, and silver-grain density within the SVZ $(c)$ at the level of the anterior commissure in juveniles (Juv) and adults $(A d)($ mean \pm SEM). $d$, The total number of silver grains overlying labeled cell clusters adjacent to the VZ within the brain parenchyma in $10-\mu \mathrm{m}$-thick tissue at the levels of area $\mathrm{X}$ and the anterior commissure in juveniles and adults of both sexes (mean \pm SEM). 


\section{HVC}

The area of the VZ at the level of HVC did not differ among the four groups (age: $F<1$; sex: $F<1$ ) (Fig. 3). However, the level of proliferation within the VZ, as measured by total number of silver grains, was higher in juveniles than adults $\left(F_{(1,16)}=5.28\right.$; $p=0.04)$ and did not differ between the sexes $(F<1)$. The density of silver grains within the VZ at this level of the telencephalon was relatively low and did not vary as a function of either age $\left(F_{(1,16)}=3.41 ; p=0.08\right)$ or sex $(F<1)$. The SVZ was not present at the level of $\mathrm{HVC}$, and clusters of thymidine labeling near the $\mathrm{VZ}$ were observed within the brain parenchyma in 9 of 10 juveniles but only in a few adults. These scattered clusters of thymidine labeling were not localized to a specific region along the dorsal-ventral axis but rather were randomly distributed along the entire extent of the VZ (Fig. 1c).

In addition to overall measurements of proliferation in the $\mathrm{VZ}$ at the level of $\mathrm{HVC}$, we also measured the incidence of thymidine labeling immediately dorsal to HVC, because it seemed possible that precursor cells HVC neurons might reside in the segment of $\mathrm{VZ}$ directly overlying HVC. If so, then there might be a higher level of thymidine incorporation in this region of the VZ. Measurements of the size of this segment of the VZ demonstrated an age difference $\left(F_{(1,10)}=5.44 ; p=0.04\right)$ but no sex difference $\left(F_{(1,10)}=1.17 ; p=0.3\right)$ (Fig. 3$)$. The age difference was because the area of VZ overlying HVC was slightly larger in adult birds than in juveniles, which presumably reflects the much larger size of HVC in adults (and hence, a greater linear stretch of VZ was measured in adults). Despite this difference, there were significantly more silver grains within this small region of VZ in juveniles than in adults $\left(F_{(1,10)}=15.90 ; p=0.003\right)$, but there was no difference between males and females at either age $\left(F_{(1,10)}=\right.$ $3.40 ; p=0.1)$. The silver-grain density within the VZ above HVC was also higher in juvenile zebra finches than in adults $\left(F_{(1,10)}=\right.$ 14.18; $p=0.004)$, and there was no sex difference $(F<1)$.

\section{Quantitative observations in $1 \mu \mathrm{m}$ sections}

The increased area of the juvenile VZ compared with that of adults indicates that VZ cells may be larger and/or more numerous in juveniles than in adults. In addition, the heightened incidence of thymidine labeling in juvenile birds suggests that many more VZ cells are actively dividing in the juvenile telencephalon. To determine which cell parameters change with age, we performed a single-cell analysis at the level of the anterior commissure within three subregions of the VZ: the VVZ, the IntVZ, and the DVZ (see Materials and Methods; Fig. $1 d$ ). To determine the degree of correspondence between our measurements of total proliferative activity in $10 \mu \mathrm{m}$ sections and this single-cell analysis, we also measured the area and total number of silver grains within each subregion of the VZ measured. In the following description, these estimates of total proliferative activity within each subregion are given first, followed by the cell analyses.

\section{$V V Z$}

Visual inspection at the level of the anterior commissure had revealed that the VVZ was thicker in juveniles than in adults (see above). Quantitative analysis confirmed that the area of each segment measured within the VVZ was significantly larger in juveniles than in adults (VVZ1, $F_{(1,22)}=36.87, p<0.0001$; VVZ2, $F_{(1,22)}=22.56, p<0.0001$ ) (Fig. $5 a$ ), but VZ area did not differ as a function of sex ( $p>0.25$ for both VVZ1 and VVZ2). Levels of proliferation within the VVZ, as measured by the total number of silver grains within each segment, were also signifi-
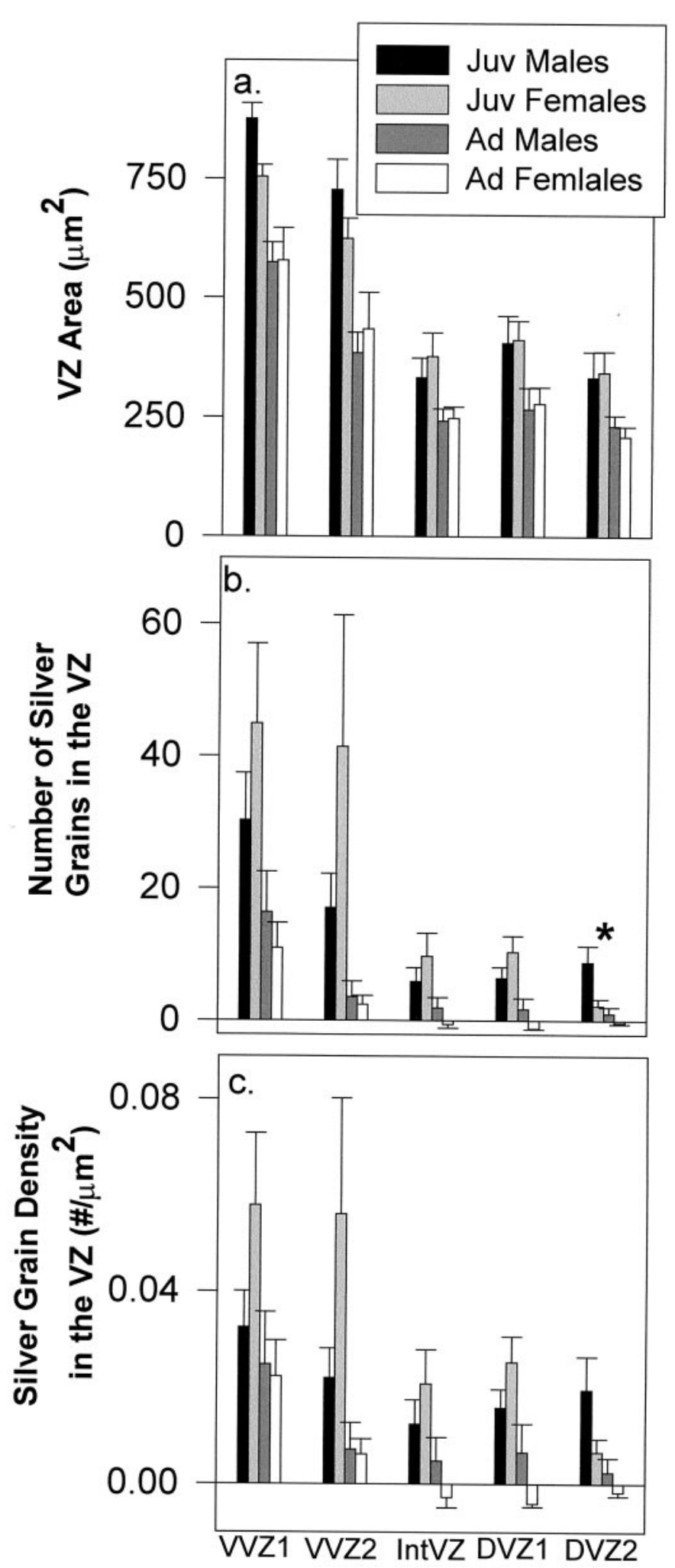

Figure 5. A $1 \mu \mathrm{m}$ tissue analysis demonstrating VZ area $(a)$, the total number of silver grains $(b)$, and silver-grain density $(c)$ (segments shown in Fig. $1 d$ ) at the level of the anterior commissure in juveniles (Juv) and adults $(A d)$ of both sexes (mean \pm SEM). The asterisk indicates a main effect of sex in the total number of silver grains in DVZ2. 
cantly higher in juveniles than adults $\left(\mathrm{VVZ1}, F_{(1,22)}=7.92, p=\right.$ $\left.0.01 ; \mathrm{VVZ2}, F_{(1,22)}=5.35, p=0.03\right)$ but showed no sex difference $(p>0.3$ for both VVZ1 and VVZ2) (Fig. $5 b)$. The silver-grain density was approximately equivalent between juveniles and adults within VVZ1 $\left(F_{(1,22)}=3.63 ; p=0.07\right)$ but was significantly higher in juveniles than adults in $\operatorname{VVZ2}\left(F_{(1,22)}=5.36 ; p=0.03\right)$ (Fig. 5c). There was no sex difference in silver-grain density within either segment of the VVZ ( $p \geq 0.25$ for both segments).

The area of individual cells within both segments of the VVZ was the same among juveniles and adults of both sexes (age: VVZ1, $F<1$; VVZ2, $F_{(1,22)}=1.69, p=0.21$; sex: $F<1$ for both VVZ1 and VVZ2) (Fig. $6 a$ ). The total number of cells (both labeled and unlabeled) was significantly greater in juveniles than adults $\left(\mathrm{VVZ1}, F_{(1,22)}=18.33, p=0.0003\right.$; VVZ2, $F_{(1,22)}=11.56$, $p=0.003)$, and there was no sex difference in cell number $(p>$ 0.15 for both segments) (Fig. $6 b$ ). The total number of thymidinelabeled cells was also significantly greater in juveniles than in adults $\left(\mathrm{VVZ1}, F_{(1,22)}=7.65, p=0.01 ; \mathrm{VVZ} 2, F_{(1,22)}=19.48, p=\right.$ 0.0002 ; sex: both $F<1$ ) (Fig. $6 c$ ). In summary, these data indicate that the increased incidence of mitotic activity in juvenile birds revealed by total silver-grain counts is attributable to a larger number of dividing cells in juveniles than adults.

The proportion and density of labeled cells were significantly higher in juveniles than adults only in V VZ2 (percentage labeled: $\mathrm{VVZ1}, F_{(1,22)}=2.78, p=0.11 ; \mathrm{VVZ} 2, F_{(1,22)}=23.13, p<$ 0.0001 ) (density labeled: VVZ1, $F<1$; VVZ2, $F_{(1,22)}=12.57$, $p=0.002$ ) (Fig. 7). There was no sex difference in the percentage of cells labeled or in the labeled cell density at either age (all values of $p>0.20$ for both percentage of cells labeled and labeled cell density in VVZ1 and VVZ2). VVZ1 lies in the more ventral aspect of the VVZ, which includes the area of out-pocketing in the VZ (Fig. 1), and this segment tended to be relatively larger and more proliferatively active than the segment of VVZ just above it (i.e., the numbers of total cells and of labeled cells were higher overall within VVZ1 than VVZ2) (Fig. 6). It is interesting that there was no selective increase in proliferation within VVZ1 of juvenile birds, as evidenced by the fact that the proportion and density of labeled cells were not different between juveniles and adults (Fig. 7). In contrast, within VVZ2, we observed not only an absolute increase in total number of cells and labeled cells in juveniles relative to adults but also an increase in the proportion and density of dividing cells in young birds.

\section{IntVZ}

The pattern of proliferation within the IntVZ at the level of the anterior commissure was similar to that seen within the VVZ. The area of the segment measured within the IntVZ was significantly greater in juveniles than in adults $\left(F_{(1,22)}=7.89 ; p=0.01\right)$, and there was no sex difference at either age $(F<1)$ (Fig. 5). The total number and density of silver grains in the IntVZ were also significantly higher in juveniles than in adults (number of silver grains: $F_{(1,22)}=8.74, p=0.007$; silver-grain density: $F_{(1,22)}=$ $7.94, p=0.01$ ) and did not vary as a function of sex (both number and density: $F<1$ ).

Measurements of cell area within the IntVZ revealed that the size of individual cells was the same among all groups (age: $F_{(1,22)}=1.14, p=0.3$; sex: $F<1$ ) (Fig. 6). The total number of IntVZ cells (both unlabeled and labeled) was greater in juveniles than adults and did not differ between males and females (age: $F_{(1,22)}=5.44, p=0.03$; sex: $\left.F<1\right)$. The total number of thymidine-labeled cells in the IntVZ was also greater in juveniles than adults and showed no sex difference (age: $F_{(1,22)}=9.00, p=$
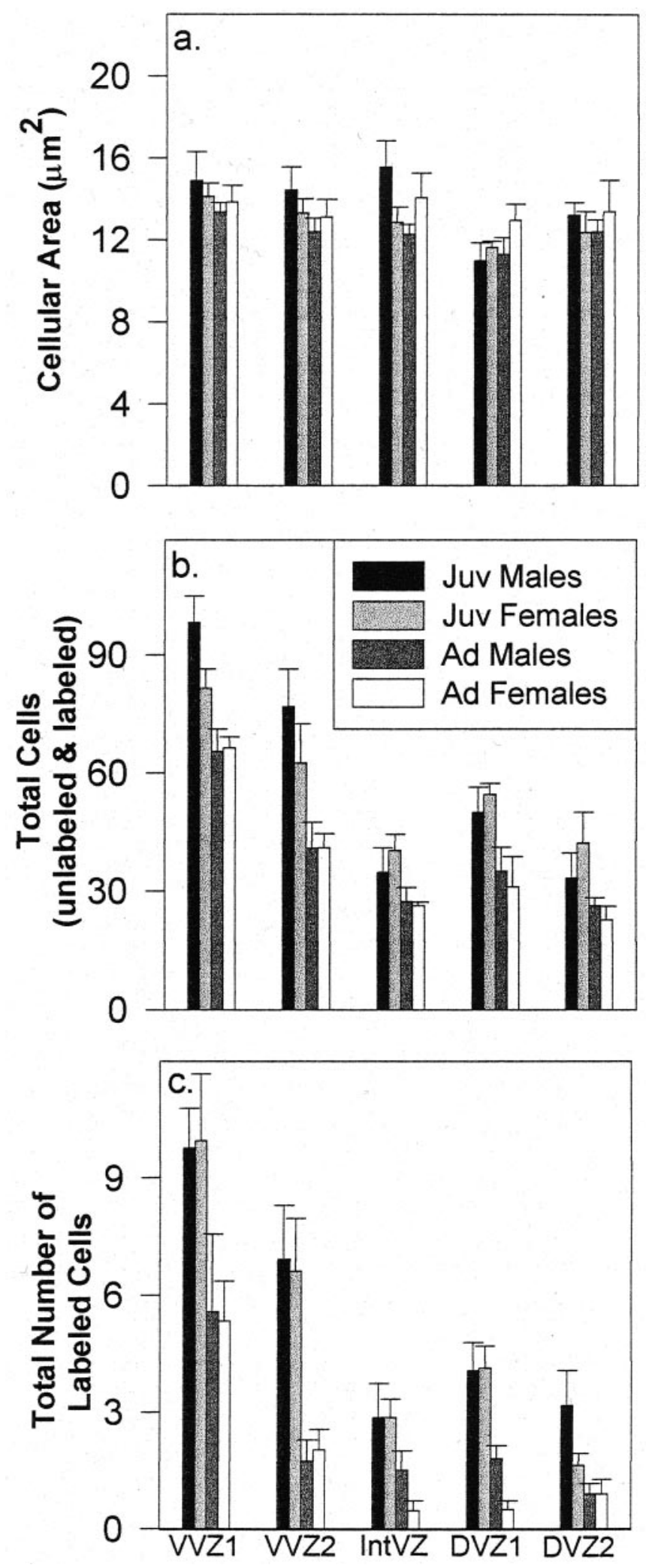

Figure 6. A $1 \mu \mathrm{m}$ tissue analysis demonstrating cellular area $(a)$, the total number of cells (labeled and unlabeled) $(b)$, and the total number of labeled cells $(c)$ within each VZ segment measured at the level of the anterior commissure in juveniles $(J u v)$ and adults $(A d)$ of both sexes $($ mean \pm SEM $)$. 

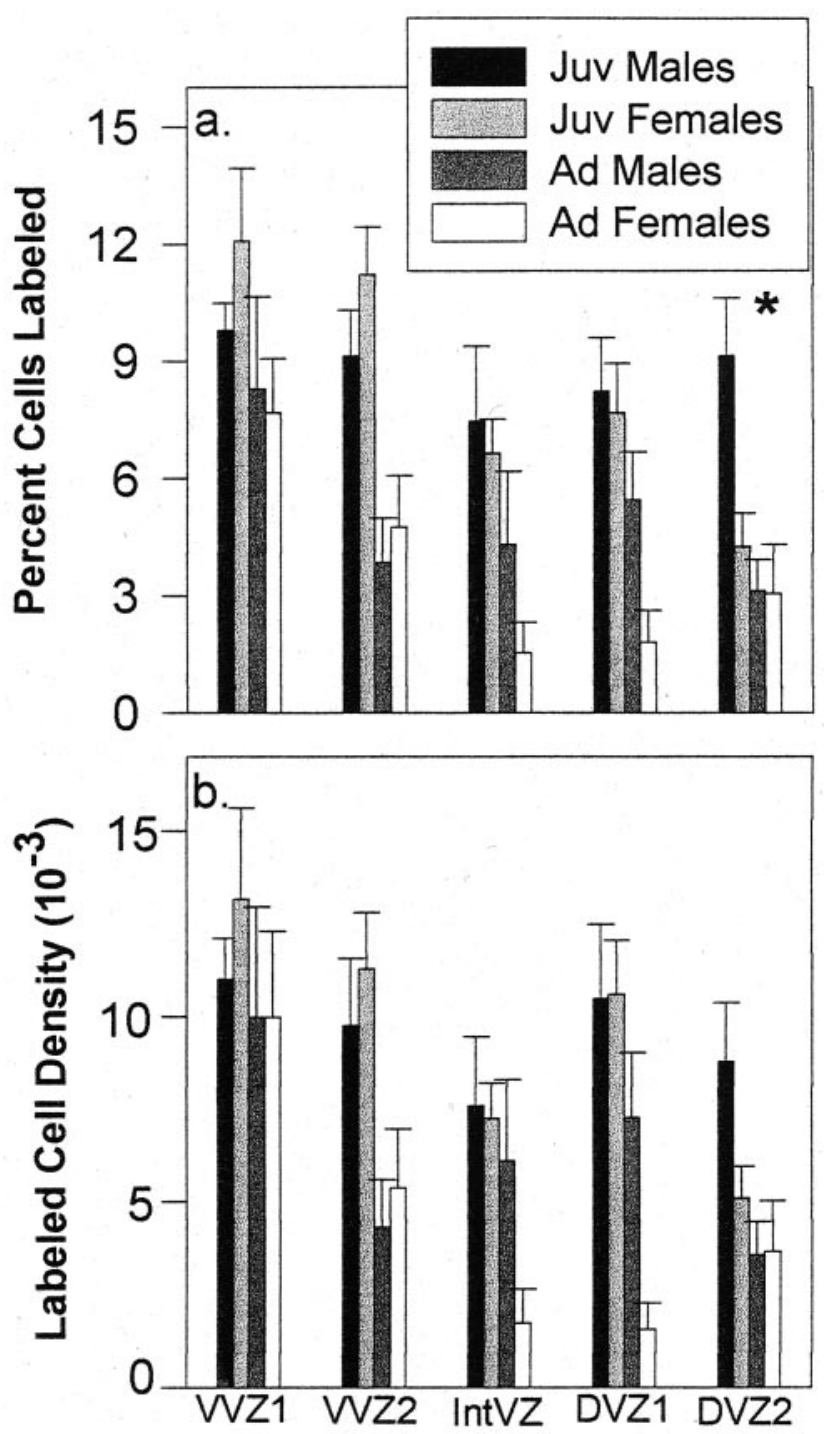

Figure 7. A $1 \mu \mathrm{m}$ tissue analysis demonstrating the percentage of cells labeled $(a)$ and labeled cell density $(b)$ within each VZ segment measured at the level of the anterior commissure in juveniles $(J u v)$ and adults $(A d)$ of both sexes (mean \pm SEM). The asterisk indicates a significant difference in the proportion of labeled cells between juvenile males and females in DVZ2.

0.007; sex: $F<1$ ). The age difference in the incidence of thymidine-labeled cells was also significant for the proportion of cells labeled (age: $F_{(1,22)}=6.77, p=0.02$; sex: $F_{(1,22)}=1.25, p=$ $0.28)$ (Fig. 7) and approached significance for labeled cell density $\left(\right.$ age: $F_{(1,22)}=4.08, p=0.06$; sex: $\left.F_{(1,22)}=1.83, p=0.19\right)$.

$D V Z$

Both segments measured within the DVZ (Fig. 1d) demonstrated an age but not a sex difference in VZ area (age: DVZ1, $F_{(1,17)}=$ $8.69, p=0.009$; DVZ2, $F_{(1,21)}=9.19, p=0.006$; sex: both $\left.F<1\right)$ (Fig. 5). The total number and density of silver grains were greater in juveniles than adults within both DVZ1 and DVZ2 (number: DVZ1, $F_{(1,17)}=23.14, p=0.0002$; DVZ2, $F_{(1,21)}=$ $12.52, p=0.002$; density: DVZ1, $F_{(1,17)}=19.77, p=0.0004$; DVZ2, $\left.F_{(1,21)}=9.67, p=0.005\right)$. There was no effect of sex on the number or density of silver grains within DVZ1 (both $F<1$ ), but there was a significant main effect of sex on both of these mea- sures within DVZ2 (number: $F_{(1,21)}=7.53, p=0.01$; density: $\left.F_{(1,21)}=4.36, p=0.05\right)$. Individual $t$ tests revealed that juvenile males had an increased total number of silver grains in DVZ2 (immediately above the $\mathrm{LH}$ fiber tract) compared with juvenile females $\left(t_{(11)}=2.56 ; p=0.03\right)$, but the incidence of thymidine labeling was equivalent among adults in this region $\left(t_{(10)}=1.23\right.$; $p=0.25)$. Individual $t$ tests for silver-grain density revealed no differences in either juveniles $\left(t_{(11)}=1.84 ; p=0.09\right)$ or adults $\left(t_{(10)}=1.13 ; p=0.28\right)$.

Measurements of individual cells in the DVZ revealed no difference in cellular area among juveniles or adults of either sex (age: DVZ1, $F_{(1,17)}=1.18, p=0.29$; DVZ2, $F<1$; sex: DVZ1, $F_{(1,17)}=2.33, p=0.15$; DVZ2, $F<1$ ) (Fig. 6). The total number of cells was greater in juveniles than in adults in both segments of the DVZ $\left(\mathrm{DVZ} 1, F_{(1,17)}=10.04, p=0.006 ; \mathrm{DVZ2}, F_{(1,21)}=5.40\right.$, $p=0.03$ ) but did not differ between males and females (both $F<$ $1)$. The number of thymidine-labeled cells was significantly greater in juveniles than adults within both segments of the DVZ $\left(\mathrm{DVZ1}, F_{(1,17)}=30.03, p<0.0001 ; \mathrm{DVZ2}, F_{(1,21)}=8.74, p=\right.$ $0.008)$, but there was no main effect of sex in the number of labeled cells $\left(\mathrm{DVZ1}, F_{(1,17)}=1.3, p=0.27\right.$; DVZ2, $F_{(1,21)}=2.27$, $p=0.15)$. Juvenile males tended to have a higher incidence of labeled cells than juvenile females in DVZ2; however, this difference was not significant $\left(t_{(11)}=1.74 ; p=0.11\right)$.

Both the proportion and density of labeled cells were higher in juveniles than adults in both DVZ segments measured (percentage labeled: DVZ1, $F_{(1,17)}=12.68, p=0.002 ;$ DVZ2, $F_{(1,21)}=$ $10.83, p=0.004$; labeled cell density: DVZ1, $F_{(1,17)}=12.93, p=$ 0.002 ; DVZ2, $\left.F_{(1,21)}=7.87, p=0.01\right)$. There was no main effect of sex within DVZ1 (percentage labeled: $F_{(1,17)}=3.0, p=0.10$; labeled cell density: $\left.F_{(1,17)}=2.78, p=0.11\right)$, but there was a main effect of sex on the proportion of cells labeled in DVZ2 (percentage labeled: $F_{(1,21)}=5.10, p=0.03$; labeled cell density: $F_{(1,21)}=$ 2.30, $p=0.14$ ) (Fig. 7). This sex difference was attributable to a larger proportion of labeled cells in males than females for juveniles $\left(t_{(11)}=2.96 ; p=0.01\right)$ but not adults $(t<1)$. Individual $t$ tests also revealed a marginal sex difference in labeled cell density for juveniles but not adults (juveniles: $t_{(11)}=2.11, p=$ 0.06; adults: $t<1$ ). The increased incidence of labeled cells in juvenile males compared with juvenile females corresponds to the same segment of the DVZ in which we observed a sex difference in the number and density of silver grains (Fig. 5b,c).

Although the total number of labeled cells tended to be greater in juvenile males than juvenile females in DVZ2 (Fig. 6), this measure was not statistically different, presumably because juvenile females had a greater total number of cells (labeled and unlabeled), thereby offsetting a sex difference in the absolute number of labeled cells. However, the proportion of labeled cells was significantly greater in juvenile males than juvenile females in DVZ2 (Fig. 7). Thus, the sex difference in thymidine labeling in the DVZ just above the LH fiber tract (DVZ2) is the result of a selective increase in the incidence of dividing cells in juvenile males compared with juvenile females.

\section{Mapping proliferation in the $\mathrm{VZ}$ at the levels of the anterior commissure and area $X$}

Our initial studies had revealed the existence of a sex difference in mitotic activity in a small segment of the VZ, as well as a spatially differentiated pattern of cell division across the VZ. To search for other examples of sex differences in proliferation and to compare levels of proliferative activity between different subregions of the VZ, we decided to map levels of thymidine labeling 

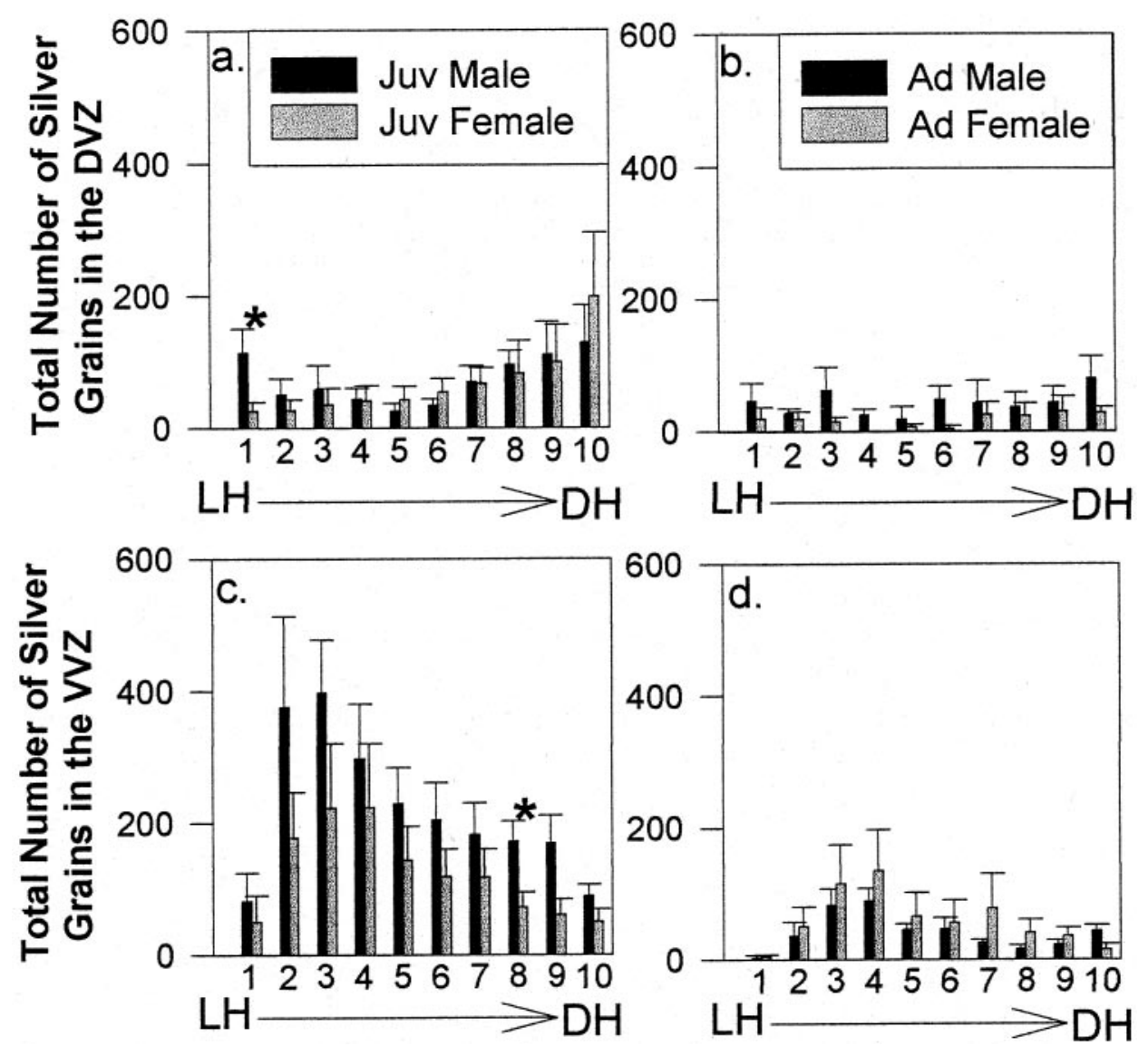

Figure 8. Histograms of the total number of silver grains within each bin of the DVZ of juveniles $(J u v)(a)$ and adults $(A d)(b)$ and in the VVZ of juveniles $(c)$ and adults $(d)$ at the level of the anterior commissure (mean \pm SEM). Asterisks indicate significant differences in thymidine labeling between juvenile males and females in DVZ bin $1(a)$ and VVZ bin $8(c)$. DH, Dorsal horn.

in $10 \%$ increments along the VVZ (from the ventral horn to the LMD fiber tract) and DVZ (from the LH fiber tract to the dorsal horn) at the levels of the anterior commissure and area $\mathrm{X}$ in 10 $\mu \mathrm{m}$ tissue sections (see Materials and Methods). These data allowed us to compare overall levels of proliferation (total number of silver grains) between the DVZ (within cortex) and the VVZ (within striatum) and to construct a map of mitotic activity along the dorsal-ventral axis for both the DVZ and VVZ at these two levels of the telencephalon.

\section{The anterior commissure}

$D V Z$. Histograms of the total number of silver grains within each $10 \%$ increment of the DVZ at the level of the anterior commissure indicated no overall effect of age or sex (age: $F_{(1,17)}=3.34$, $p=0.09$; sex: $F<1$ ) (Fig. $8 a, b)$. However, there was a main effect of bins $\left(F_{(9,153)}=4.47 ; p<0.0001\right)$, indicating that the level of proliferation varied along the dorsal-ventral axis of the DVZ. The incidence of cell division was highest near the dorsal horn in juvenile males and females (Fig. 8a, bins 8-10). These three bins at the tip of the DVZ are adjacent to the dorsal horn of the lateral ventricles and correspond to a region of increased mitotic activity described by Alvarez-Buylla et al. (1990) in adult canaries at the same location. Comparisons of the total number of silver grains within individual bins revealed a sex difference in thymidine labeling in bin 1, just dorsal to the $\mathrm{LH}$, between juvenile males and females (but not adults). That is, juvenile males had significantly more silver grains in the segment immediately above the LH than did juvenile females $\left(t_{(9)}=2.42 ; p=0.04\right)$. This sex difference in proliferation is located in the same segment of the DVZ as the sex difference in the proportion of thymidine-labeled cells we observed in the $1 \mu \mathrm{m}$ tissue analysis (see above). Bins 2-10 did not reveal other regions of sexually dimorphic proliferation in either juveniles or adults.

$V V Z$. The pattern of thymidine labeling along the dorsalventral axis of the $\mathrm{VVZ}$ at the level of the anterior commissure was similar between juveniles and adults of both sexes, with the highest levels of proliferation occurring near the ventral horn (in bins 2, 3, and 4) (Fig. 8c,d). This area resides within the region of the VVZ that bulges out into the brain parenchyma as an outpocketing of the VZ (Fig. 2), which corresponds to a region of increased mitotic activity referred to as a proliferative hot spot close to the ventral horn of the lateral ventricles (AlvarezBuylla et al., 1990). Total silver-grain counts revealed that proliferation was higher throughout the VVZ in juveniles than in adults $\left(F_{(1,17)}=11.44 ; p=0.004\right)$, but there was no main effect of sex $\left(F_{(1,17)}=1.17 ; p=0.30\right)$. There was also a main effect of bins and an age-by-bins interaction (bins: $F_{(9,153)}=8.76, p<0.0001$; age by bins: $\left.F_{(9,153)}=2.55, p=0.009\right)$, reflecting the higher levels of proliferation near the ventral horn, particularly in juvenile animals.

A sex difference in the total number of silver grains within individual bins was seen in bin 8 for juvenile animals, with males having higher levels of proliferative activity than females (bin 8: $\left.t_{(9)}=2.58 ; p=0.03\right)$, and this difference approached significance in bin $9\left(t_{(9)}=2.12 ; p=0.06\right)$. The total number of silver grains in individual bins within the $\mathrm{VVZ}$ of adults did not reveal sexually dimorphic mitotic activity. This pattern of results indicates that a segment of the VVZ lying ventral to the LMD fiber tract in the striatum contains a region of sexually dimorphic 


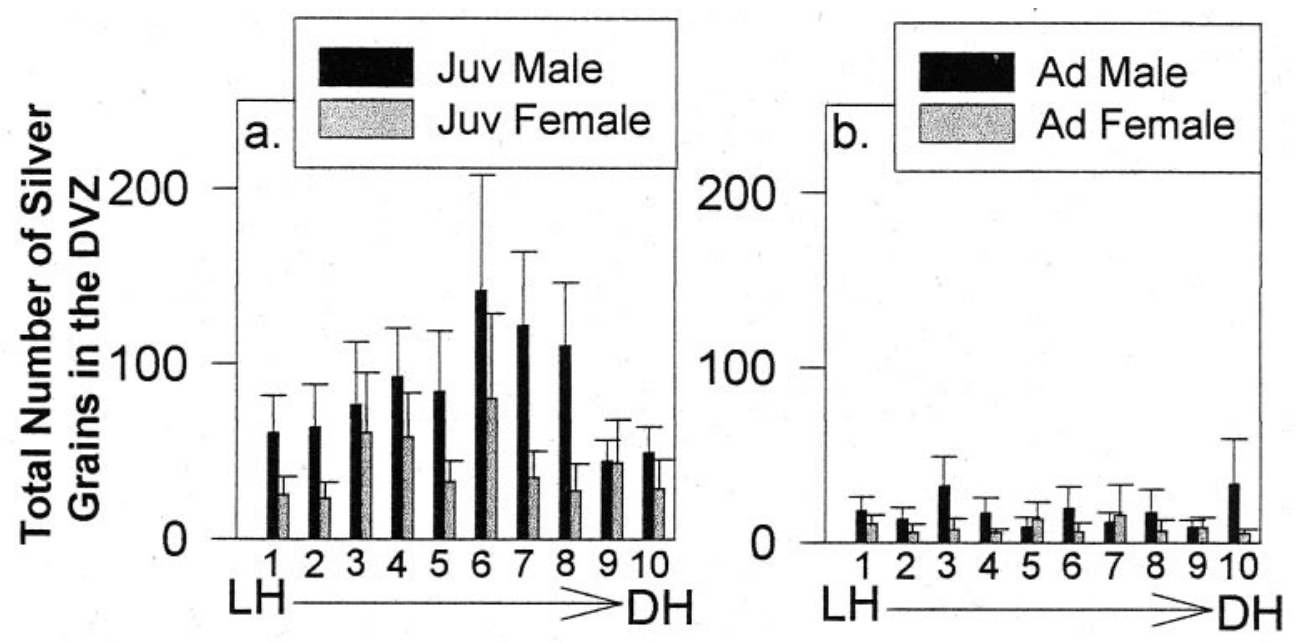

Figure 9. Histograms of the total number of silver grains within each bin of the DVZ of juveniles (Juv) $(a)$ and adults $(A d)(b)$ and in the VVZ of juveniles $(c)$ and adults $(d)$ at rostral levels of area X (mean \pm SEM). Asterisks in $c$ indicate significant differences in thymidine labeling between juvenile males and females in VVZ bins 1, 2, 4, and 5. $D H$, Dorsal horn.
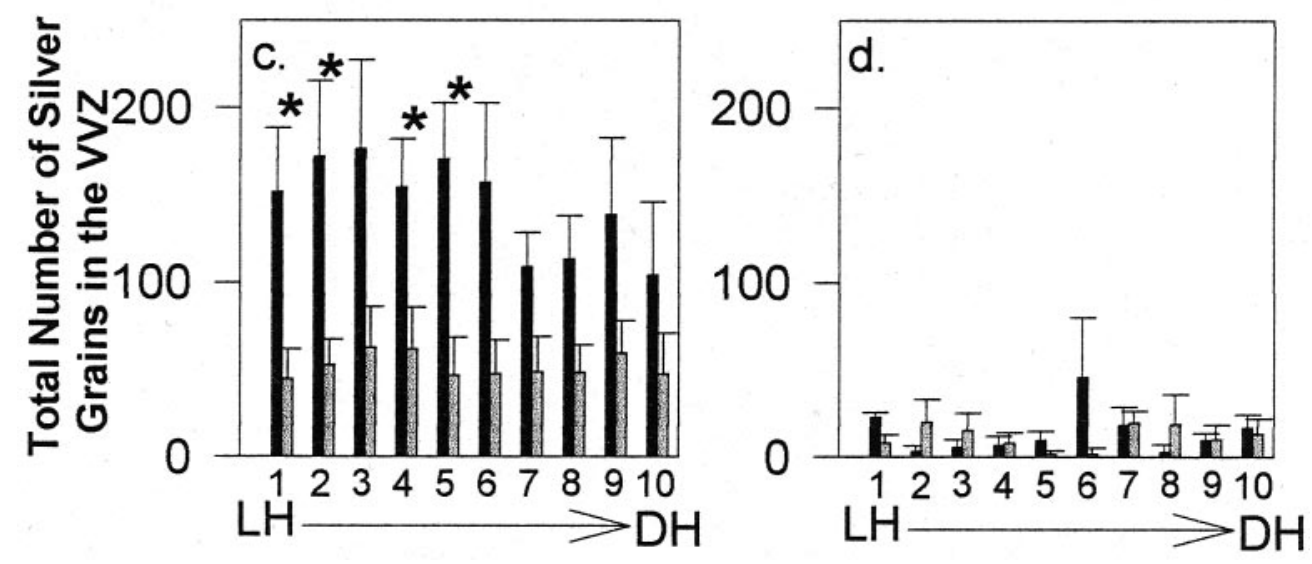

proliferative activity in juveniles but not adults. In addition, there is a consistent trend toward higher levels of proliferation in juvenile males than juvenile females throughout the dorsal-ventral extent of the $\mathrm{VVZ}$ at the level of the anterior commissure $\left(F_{(1,17)}=3.75, p=0.07\right.$ for juvenile males vs females) (Fig. $\left.8 c\right)$.

\section{Area $X$}

$D V Z$. Thymidine labeling in the DVZ at the level of area $\mathrm{X}$ did not demonstrate a strong pattern of spatially differentiated proliferation in juveniles or adults (Fig. $9 a, b$ ). The total number of silver grains across bins demonstrated an age difference in the incidence of thymidine labeling $\left(F_{(1,18)}=7.63 ; p=0.01\right)$, reflecting a more than twofold increase in overall levels of mitotic activity in juveniles compared with adults. There was no main effect of $\operatorname{sex}\left(F_{(1,18)}=2.14 ; p=0.16\right)$ or bins $\left(F_{(9,162)}=1.83 ; p=\right.$ $0.07)$. The total number of silver grains in bin 1 (immediately dorsal to the $\mathrm{LH}$ ) of juvenile males and females revealed no sex difference $\left(t_{(10)}=1.50 ; p=0.17\right)$. Thus, the pattern of sexually dimorphic labeling we observed just dorsal to the $\mathrm{LH}$ at the level of the anterior commissure (more silver grains in bin 1 of juvenile males) (Figs. 5b, $8 a$ ) did not extend rostrally to this level of the telencephalon.

$V V Z$. The spatial distribution of thymidine labeling along the dorsal-ventral axis of the V VZ at the level of area X was different among males and females at both ages (Fig. 9c, $d$ ). Juvenile males demonstrated a slight increase in the total number of silver grains in bins 1-6, followed by lower levels between bins 7 and 10 , whereas juvenile females demonstrated relatively consistent levels of proliferative activity in bins 1-10. Adults did not demonstrate as much change in the spatial distribution of thymidine labeling, and both males and females demonstrated low levels of proliferation throughout the VVZ at this level. Statistical analysis revealed an overall effect of age, sex, and an age-by-sex interaction $\left(\right.$ age: $F_{(1,17)}=17.35, p=0.0006$; sex: $F_{(1,17)}=5.40, p=0.03$; age by sex: $\left.F_{(1,17)}=4.84, p=0.04\right)$ but no effect of bins $(F<1)$. Overall, juvenile males had higher levels of proliferation throughout the VVZ than juvenile females $\left(F_{(1,17)}=10.70 ; p=0.005\right)$, but levels of thymidine labeling were equivalent in adults $(F<1)$. When we compared thymidine labeling within individual bins between juvenile males and females, bins 1, 2, 4, and 5 demonstrated sex differences in proliferation and a tendency toward a sex difference in bins $3,6,7$, and 8 (bin 1: $t_{(9)}=2.46, p=0.04$; bin $2: t_{(9)}=2.40, p=0.04$; bin $3: t_{(9)}=1.89, p=0.09$; bin $4: t_{(9)}=$ $2.50, p=0.04$; bin $5: t_{(9)}=3.02, p=0.02$; bin $6: t_{(9)}=2.07, p=$ 0.07 ; bin 7: $t_{(9)}=2.13, p=0.06$; bin 8: $\left.t_{(9)}=2.12, p=0.06\right)$. Interestingly, the segment of the VVZ containing bins 4 and 5 is located approximately adjacent to area $X$, raising the possibility that this region of the $\mathrm{VZ}$ (and adjacent regions at this level) might contain precursor cells that produce area $\mathrm{X}$ neurons.

\section{Comparing levels of proliferation between the VVZ and the DVZ}

To directly compare both area and levels of proliferation between the DVZ and the VVZ, we collapsed the binned data from our mapping study within each of these regions at the levels of the anterior commissure and area X (Fig. 10). 

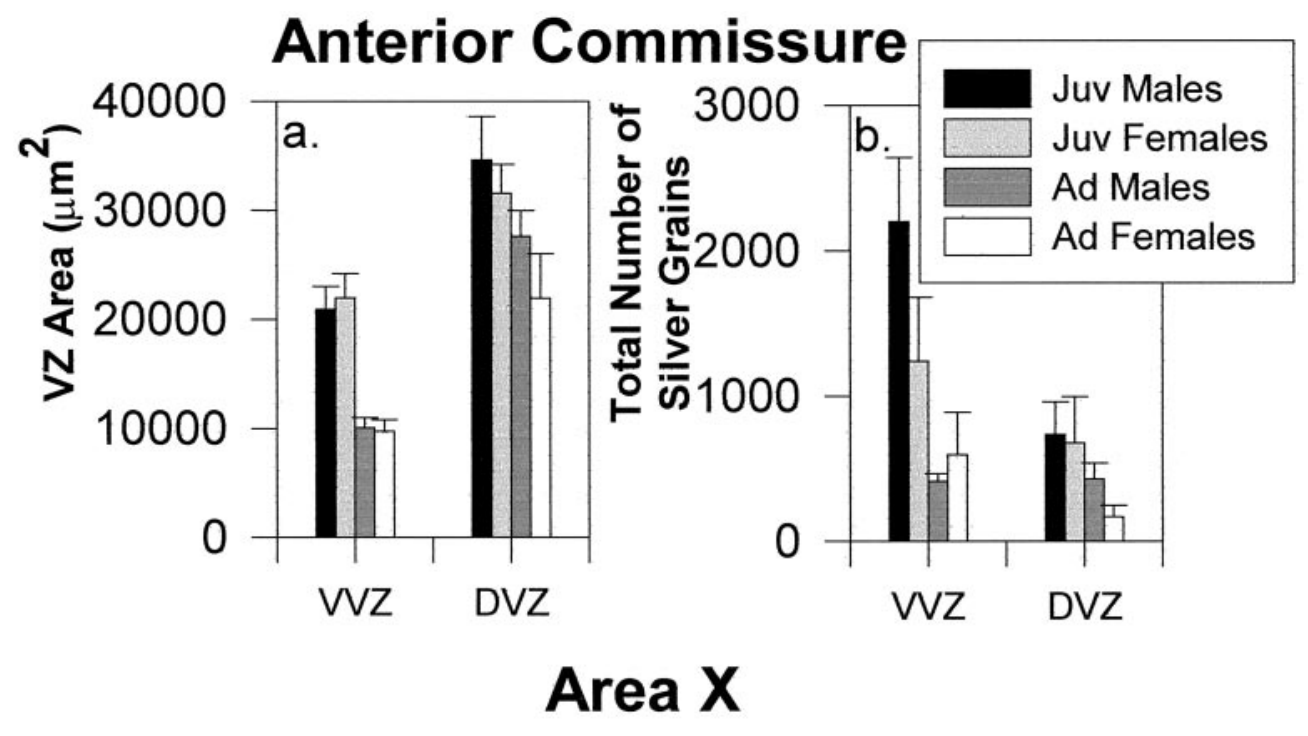

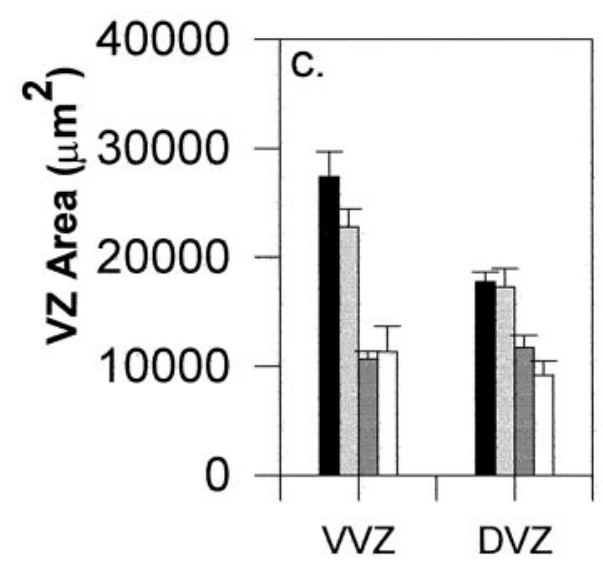

\section{Anterior commissure}

The area of the entire DVZ was greater than that of the VVZ at the level of the anterior commissure $\left(F_{(1,18)}=72.85 ; p<0.0001\right)$. This increased area of the DVZ was attributable to the fact that the linear length of the DVZ was much greater than that of the VVZ at this level of the brain (data not shown). Thus, the enlarged area of the VVZ close to the ventral horn (see above) was offset by the greater length of the DVZ at the anterior commissure. As expected, there was also a main effect of age, reflecting the larger area of both the VVZ and DVZ in juveniles $\left(F_{(1,18)}=25.01 ; p<0.0001\right)$. The total number of silver grains was higher in the VVZ than the DVZ at this level, despite the smaller area of the $\operatorname{VVZ}\left(F_{(1,18)}=19.29 ; p=0.0004\right)$. There was also a main effect of age for number of silver grains $\left(F_{(1,18)}=10.70 ; p=\right.$ $0.004)$, no effect of sex $\left(F_{(1,18)}=1.22 ; p=0.28\right)$, and an age-bysex-by-region interaction $\left(F_{(1,18)}=5.95 ; p=0.03\right)$. This interaction was attributable to a sex difference in the VVZ but not the DVZ of juvenile birds (juvenile males vs females in VVZ: $F_{(1,18)}$ $=4.37 ; p=0.05$ ), whereas adult males and females were not different in either region. There was also an age-by-region interaction $\left(F_{(1,18)}=8.53 ; p=0.009\right)$, reflecting the fact that the number of silver grains was greater in the VVZ than the DVZ for juveniles $\left(F_{(1,18)}=29.42 ; p<0.0001\right)$ but not for adults $(F<1)$. This pattern indicates that the higher level of proliferative activity in the VVZ than the DVZ is unique to juveniles and is presumably primarily a result of the presence of the hot spot of labeling in the pronounced out-pocketing of the VVZ seen in juveniles along the ventralmost aspect of the lateral ventricles at this level (Fig. 2). In summary, levels of proliferation were significantly higher within the VVZ than the DVZ at the level of the anterior commissure in juvenile but not adult brains, with the highest levels of mitotic activity occurring within the VVZ of juvenile males compared with juvenile females or adults.

\section{Area $X$}

Collapsing across bins from the DVZ versus the VVZ at the level of area $\mathrm{X}$ indicated a larger area in the VVZ than the DVZ $\left(F_{(1,18)}=26.25 ; p<0.0001\right)$ and a nonsignificant trend toward higher levels of thymidine labeling in the $\operatorname{VVZ}\left(F_{(1,18)}=3.66\right.$; $p=0.07$ ) (Fig. 10c,d). Thus, the higher levels of proliferation evident in the VVZ of juveniles at the level of the anterior commissure were less evident at this more rostral level of the brain. (However, it was true that the incidence of mitotic activity at this level was higher within a restricted region of the VVZ close to the ventral horn, although this pattern was much less pronounced at area $X$ than at the anterior commissure; see qualitative description above.) The areas of both the DVZ and VVZ were larger in juveniles than adults (main effect of age: $\left.F_{(1,18)}=57.91 ; p<0.0001\right)$ and did not vary as a function of sex $\left(F_{(1,18)}=1.60 ; p=0.22\right)$. In addition, juveniles had significantly greater numbers of silver grains in both the DVZ and VVZ (main effect of age: $\left.F_{(1,18)}=16.83 ; p=0.0007\right)$, and there was an effect 
of sex on levels of proliferation $\left(F_{(1,18)}=5.04 ; p=0.04\right)$ that was attributable to higher levels of mitotic activity in juvenile males than females within the $\operatorname{VVZ}\left(F_{(1,18)}=12.46 ; p=0.002\right)$ but not the $\operatorname{DVZ}\left(F_{(1,18)}=3.14 ; p=0.09\right)$. Thus, juvenile males demonstrate higher overall levels of proliferative activity throughout the VVZ compared with juvenile females at this level of the brain. This robust sex difference occurs within a region of the $\mathrm{VZ}$ that is in close proximity to area $\mathrm{X}$ (compare Fig. $9 c$ ).

\section{DISCUSSION}

The vast majority of studies investigating neurogenesis in the telencephalon of songbirds have focused on observing new neuron addition and/or seasonal neuronal turnover within songcontrol nuclei (Goldman and Nottebohm, 1983; E. J. Nordeen and K. W. Nordeen, 1988; K. W. Nordeen and E. J. Nordeen, 1988; Kirn et al., 1994). Because new neurons require $\sim 1-3$ weeks to arrive in song-control nuclei after their generation within the VZ (Burd and Nottebohm, 1985; Alvarez-Buylla and Nottebohm, 1988; Burek et al., 1994; Kirn et al., 1999), the long post-thymidine intervals required in such studies make it impossible to determine the relative contributions of proliferation, migration, differentiation, and cell death. Because all of these processes influence neurogenesis, it is impossible to know what proportion of the newly generated cells within the VZ are destined to become neurons. Thus, our data do not assess the rate at which new neurons are created within the VZ. Rather, these results directly measure the incidence of cell division in the VZ, and hence the contribution that different levels of mitotic activity can potentially make to neuronal addition in male and female zebra finches during song development and adulthood. Two major findings have emerged: The enhanced incidence of cell division seen in juvenile relative to adult brains correlates with rapid growth and neuron addition to the song-control nuclei of HVC and area $\mathrm{X}$ in young males, indicating that the higher levels of proliferation seen during vocal learning could contribute directly to the growth of song-control nuclei. Furthermore, we observed restricted regions of developmentally regulated sexually dimorphic proliferation in which the incidence of cell division was higher in juvenile males than juvenile females, especially at the level of area X. Cells born within such regions might contribute to the sexually dimorphic growth of song-control nuclei that occurs during the sensitive period for vocal learning.

\section{Mitotic activity within the VZ is spatially differentiated throughout the telencephalon}

Although mitotic activity was ubiquitous throughout the telencephalon of both juveniles and adults, a highly nonuniform pattern of proliferation occurred within the VZ, with the highest levels at the anterior commissure and lower levels at area $\mathrm{X}$ and HVC. This pattern suggests that the location of precursor cells that give rise to song-control neurons may be spatially remote from their target. However, a region with consistently higher levels of mitotic activity in juvenile males than females occurs in close proximity to area $X$, suggesting that this region may give rise to area $\mathrm{X}$ neurons.

There was also a difference in the total amount of proliferative activity between the DVZ and VVZ in juveniles (but not adults) at the level of the anterior commissure, where overall levels of proliferation were substantially higher within the VVZ than within the DVZ of young birds (Fig. 10). The VVZ of juveniles contained a prominent out-pocketing of the neuroepithelium (Fig. 2) that might represent a remnant of a sulcus such as the one that divides the medial and lateral ganglionic eminences, which are thought to generate cells destined for the striatum and pallidum, respectively, in embryonic mammals (Smart and Sturrock, 1979). The enhanced proliferative activity within the VVZ (relative to the DVZ) of juveniles is interesting, because it correlates with a large addition of new neurons to the striatum of songbirds during the first several weeks after hatching, whereas the neighboring cortex receives many fewer new neurons (Alvarez-Buylla et al., 1994).

We do not know whether cells generated in the dorsal versus ventral proliferative zones are restricted to the cortex and basal ganglia, respectively. However, this seems possible, because studies of telencephalic development have provided evidence for migrational boundaries that prevent movement across the corticostriatal sulcus of the VZ or from postmitotic cortex to striatum (Fishell et al., 1993; Neyt et al., 1997; Striedter et al., 1998). Because the SVZ generates both neurons and glia (Smart, 1961; Lois and Alvarez-Buylla, 1993; Szele and Chesselet, 1996; Doetsch et al., 1999), it is possible that this proliferative zone in conjunction with the VVZ generates both cell types within the striatum, whereas the DVZ might be a source of new neurons and glia in the cortex [glia dividing in situ presumably contribute to glial turnover throughout the telencephalon (Cameron and Rakic, 1991)]. However, numerous studies have also provided evidence for extensive tangential migration of neurons both within and between the striatum and cortex (O'Rourke et al., 1995; Anderson et al., 1997; Lavdas et al., 1999).

\section{Proliferation is higher in juveniles than in adults}

Overall levels of telencephalic proliferation are much higher in 30-d-old juvenile birds than adults, although brain size and mass have achieved adult levels by $30 \mathrm{~d}$ of age. These results are consistent with previous work in birds showing that neurogenesis decreases with age but continues into adulthood (Alvarez-Buylla et al., 1994; Ling et al., 1997). We found that the area of the VZ was significantly larger in juveniles than in adults throughout the telencephalon. Measurements of the total number of silver grains to estimate overall levels of mitotic activity revealed significantly higher levels of cell division within the VZ of juvenile zebra finches than adults at the levels of area $X$, the anterior commissure, and HVC (including the VZ immediately above HVC). Our single-cell analysis at the level of the anterior commissure showed that the enlarged VZ of juveniles was attributable to a larger number of cells, such that the total number of cells in the VZ decreases over the course of development. The VZ of juveniles also had a larger number of thymidine-labeled cells than did the VZ adults, indicating that the increased incidence of mitotic activity in juvenile birds as revealed by total silver-grain counts is attributable to a larger number of dividing cells in juveniles than in adults. The decrease in VZ cell number may involve either a terminal division of stem cells and their migration away from the $\mathrm{VZ}$ and/or the death of stem cells within the VZ.

Telencephalic regions not involved with song learning appear to achieve their adult size by $\sim 30 \mathrm{~d}$ of age in zebra finches, whereas song-control regions continue to show large-scale morphological changes in size and neuron number thereafter, during the period of vocal learning (Bottjer et al., 1985). Because the majority of brain development is complete by $30 \mathrm{~d}$, it is surprising that relatively high rates of proliferative activity within the VZ are maintained in juveniles. In fact, more new cells are generated than could presumably be incorporated into the brain. Therefore, the majority of new cells must die en route to their final destina- 
tion or after they have reached their targets. Alternatively, a high level of cell turnover throughout the brain must occur to accommodate the arrival and subsequent incorporation of new neurons (i.e., older cells must die, at least within certain phenotypic populations) (Alvarez-Buylla et al., 1988). Approximately onehalf of newly generated neurons die between the second and third weeks after their arrival in HVC (Kirn et al., 1999), suggesting that newly generated cells from the $\mathrm{VZ}$ undergo cell death if they are not incorporated into functional circuitry within some finite period after the end of migration. This idea suggests that there is a discrete window of time in which young neurons produced in the avian telencephalon must receive appropriate trophic support (i.e., growth- or activity-dependent factors) if they are to survive (Rasika et al., 1999; Johnson et al., 2000).

\section{Sex differences in proliferation}

A major finding of the present study is that specific regions of the VZ demonstrate sexually dimorphic cell division in juvenile birds. Previous studies examining cell proliferation in various sexually dimorphic systems have reported no evidence for differential cell division between males and females (Jacobson and Gorski, 1981; Breedlove et al., 1983; Gorlick and Kelley, 1987), suggesting that the development of sexually dimorphic brain regions may result primarily from sex differences in migration, differentiation, and/or neuron death (Kirn and DeVoogd, 1989; Burek et al., 1997). The incidence of newly generated neurons within $\mathrm{HVC}$ is sexually dimorphic in juvenile zebra finches $9 \mathrm{~d}$ after thymidine administration, before most new neurons in a thymidine-labeled cohort have migrated into HVC (Burek et al., 1994). However, it is impossible to know whether this difference results at least in part from sex differences in migration, differentiation, or cell death (for example, many labeled pyknotic cells are seen in areas of migrating neurons in adult canaries) (Alvarez-Buylla and Nottebohm, 1988). In general, it is extremely difficult to resolve mechanisms of sexually dimorphic neuron addition, because the location of precursor cells within the VZ that give rise to neurons destined for highly specific brain regions such as HVC and area $\mathrm{X}$ is unknown. By dividing the VZ into discrete segments, we discovered regions of sexually dimorphic proliferation. In particular, we found higher levels of cell division in juvenile males than females within segments of the DVZ and VVZ at the level of the anterior commissure, as well as a highly sexually dimorphic region within the VVZ at the level of area $\mathrm{X}$ (van Praag et al., 1999; Perfilieva et al., 2001).

A large-scale mapping study of the $\mathrm{VZ}$ across different ages seems likely to reveal additional areas of sexually dimorphic proliferation. For example, regions of sexually dimorphic mitotic activity may shift as patterns of growth for different song-control nuclei change. Identifying regions of sexually dimorphic mitotic activity would permit a more sensitive test of the role of steroid hormones in neuronal production and might alter the conclusions of past studies indicating that sex hormones have little or no influence on cell proliferation (Goldman and Nottebohm, 1983; Brown et al., 1993; Rasika et al., 1994). Any selective increase in the genesis of neuroblasts fated to become song-control neurons in juvenile males could contribute to the construction of sexually dimorphic song-control regions. Thus, our observation of increased proliferation within restricted regions of the $\mathrm{VZ}$ of juvenile males may indicate potential sites of stem cells that give rise to song-control neurons during the sensitive period for vocal learning. This idea is supported by the finding that the incorporation of new neurons into $\mathrm{HVC}$ is greater in juvenile males than females (K. W. Nordeen and E. J. Nordeen, 1988); to the best of our knowledge, it is not known whether the low level of new neuron incorporation in the adult HVC is dimorphic. Our data indicate that the number of cells (both labeled and unlabeled) in the VZ decreases as zebra finches mature. Therefore, we conclude that the number of progenitor cells that are sexually dimorphic in young birds decreases over the course of development. By the time a bird reaches adulthood, there are no longer regions of sexually dimorphic proliferative activity within the VZ.

\section{REFERENCES}

Alvarez-Buylla A, Kirn JR (1997) Birth, migration, incorporation, and death of vocal control neurons in adult songbirds. J Neurobiol 33:585-601.

Alvarez-Buylla A, Nottebohm F (1988) Migration of young neurons in adult avian brain. Nature 335:353-354.

Alvarez-Buylla A, Theelen M, Nottebohm F (1988) Birth of projection neurons in the higher vocal center of the canary forebrain before, during, and after song learning. Proc Natl Acad Sci USA 85:8722-8726.

Alvarez-Buylla A, Theelen M, Nottebohm F (1990) Proliferation "hot spots" in adult avian ventricular zone reveal radial cell division. Neuron 5:101-109.

Alvarez-Buylla A, Ling CY, Nottebohm F (1992) High vocal center growth and its relation to neurogenesis, neuronal replacement and song acquisition in juvenile canaries. J Neurobiol 23:396-406.

Alvarez-Buylla A, Ling CY, Yu WS (1994) Contribution of neurons born during embryonic, juvenile, and adult life to the brain of adult canaries: regional specificity and delayed birth of neurons in the songcontrol nuclei. J Comp Neurol 347:233-248.

Anderson SA, Eisenstat DD, Shi L, Rubenstein JL (1997) Interneuron migration from basal forebrain to neocortex: dependence on Dlx genes. Science 278:474-476.

Böhner J (1990) Early acquisition of song in the zebra finch. Anim Behav 39:369-374.

Bottjer SW, Glaessner SL, Arnold AP (1985) Ontogeny of brain nuclei controlling song learning and behavior in zebra finches. $\mathrm{J}$ Neurosci $5: 1556-1562$.

Bottjer SW, Miesner EA, Arnold AP (1986) Changes in neuronal number, density and size account for increases in volume of song-contro nuclei during song development in zebra finches. Neurosci Lett 67:263-268.

Bottjer SW, Halsema KA, Brown SA, Miesner EA (1989) Axonal connections of a forebrain nucleus involved with vocal learning in zebra finches. J Comp Neurol 279:312-326.

Boulder Committee (1970) Embryonic vertebrate central nervous system: revised terminology. Anat Rec 166:257-261.

Breedlove SM, Jordan CL, Arnold AP (1983) Neurogenesis of motoneurons in the sexually dimorphic spinal nucleus of the bulbocavernosus in rats. Brain Res 285:39-43.

Brown SD, Johnson F, Bottjer SW (1993) Neurogenesis in adult canary telencephalon is independent of gonadal hormone levels. J Neurosci 13:2024-2032.

Burd GD, Nottebohm F (1985) Ultrastructural characterization of synaptic terminals formed on newly generated neurons in a song control nucleus of the adult canary forebrain. J Comp Neurol 240:143-152.

Burek MJ, Nordeen KW, Nordeen EJ (1994) Ontogeny of sex differences among newly-generated neurons of the juvenile avian brain. Brain Res Dev Brain Res 78:57-64.

Burek MJ, Nordeen KW, Nordeen EJ (1997) Sexually dimorphic neuron addition to an avian song-control region is not accounted for by sex differences in cell death. J Neurobiol 33:61-71.

Cameron RS, Rakic P (1991) Glial cell lineage in the cerebral cortex: a review and synthesis. Glia 4:124-137.

Caviness Jr VS, Takahashi T, Nowakowski RS (1995) Numbers, time and neocortical neuronogenesis: a general developmental and evolutionary model. Trends Neurosci 18:379-383.

Doetsch F, Caille I, Lim DA, Garcia-Verdugo JM, Alvarez-Buylla A (1999) Subventricular zone astrocytes are neural stem cells in the adult mammalian brain. Cell 97:703-716.

Fishell G, Mason CA, Hatten ME (1993) Dispersion of neural progenitors within the germinal zones of the forebrain. Nature 362:636-638

Garcia-Verdugo JM, Doetsch F, Wichterle H, Lim DA, Alvarez-Buylla A (1998) Architecture and cell types of the adult subventricular zone: in search of the stem cells. J Neurobiol 36:234-248.

Goldman SA, Nottebohm F (1983) Neuronal production, migration, and differentiation in a vocal control nucleus of the adult female canary brain. Proc Natl Acad Sci USA 80:2390-2394.

Gorlick DL, Kelley DB (1987) Neurogenesis in the vocalization pathway of Xenopus laevis. J Comp Neurol 257:614-627.

Herrmann K, Bischof HJ (1986) Delayed development of song control 
nuclei in the zebra finch is related to behavioral development. J Comp Neurol 245:167-175.

Jacobson CD, Gorski RA (1981) Neurogenesis of the sexually dimorphic nucleus of the preoptic area in the rat. J Comp Neurol 196:519-529.

Johnson F, Norstrom E, Soderstrom K (2000) Increased expression of endogenous biotin, but not BDNF, in telencephalic song regions during zebra finch vocal learning. Brain Res Dev Brain Res 120:113-123.

Kirn J, O'Loughlin Kasparian BS, Nottebohm F (1994) Cell death and neuronal recruitment in the high vocal center of adult male canaries are temporally related to changes in song. Proc Natl Acad Sci USA 91:7844-7848.

Kirn JR, DeVoogd TJ (1989) Genesis and death of vocal control neurons during sexual differentiation in the zebra finch. $J$ Neurosci 9:3176-3187.

Kirn JR, Fishman Y, Sasportas K, Alvarez-Buylla A, Nottebohm F (1999) Fate of new neurons in adult canary high vocal center during the first 30 days after their formation. J Comp Neurol 411:487-494.

Lavdas AA, Grigoriou M, Pachnis V, Parnavelas JG (1999) The medial ganglionic eminence gives rise to a population of early neurons in the developing cerebral cortex. J Neurosci 19:7881-7888.

Ling C, Zuo M, Alvarez-Buylla A, Cheng MF (1997) Neurogenesis in juvenile and adult ring doves. J Comp Neurol 379:300-312.

Lois C, Alvarez-Buylla A (1993) Proliferating subventricular zone cells in the adult mammalian forebrain can differentiate into neurons and glia. Proc Natl Acad Sci USA 90:2074-2077.

Neyt C, Welch M, Langston A, Kohtz J, Fishell G (1997) A short-range signal restricts cell movement between telencephalic proliferative zones. J Neurosci 17:9194-9203.

Nordeen EJ, Nordeen KW (1988) Sex and regional differences in the incorporation of neurons born during song learning in zebra finches. J Neurosci 8:2869-2874.

Nordeen KW, Nordeen EJ (1988) Projection neurons within a vocal motor pathway are born during song learning in zebra finches. Nature 334:149-151.
Nottebohm F, Arnold AP (1976) Sexual dimorphism in vocal control areas of the songbird brain. Science 194:211-213.

Nottebohm F, Kelley DB, Paton JA (1982) Connections of vocal control nuclei in the canary telencephalon. J Comp Neurol 207:344-357.

O'Rourke NA, Sullivan DP, Kaznowski CE, Jacobs AA, McConnell SK (1995) Tangential migration of neurons in the developing cerebral cortex. Development 121:2165-2176.

Perfilieva E, Risedal A, Nyberg J, Johansson B, Eriksson PS (2001) Gender and strain influence on neurogenesis in dentate gyrus of young rats. J Cereb Blood Flow Metab 21:211-217.

Rasika S, Nottebohm F, Alvarez-Buylla A (1994) Testosterone increases the recruitment and/or survival of new high vocal center neurons in adult female canaries. Proc Natl Acad Sci USA 91:7854-7858.

Rasika S, Alvarez-Buylla A, Nottebohm F (1999) BDNF mediates the effects of testosterone on the survival of new neurons in an adult brain. Neuron 22:53-62.

Smart I (1961) The subependymal layer in the mouse brain and its cell production as shown by autoradiography after thymidine $-{ }^{3} \mathrm{H}$ injection. J Comp Neurol 116:325-347.

Smart I, Sturrock RR (1979) Ontogeny of the neostriatum. In: The neostriatum (Divac I, Oberg RGE, eds), pp 127-146. Oxford: Pergamon.

Striedter GF, Marchant TA, Beydler S (1998) The "neostriatum" develops as part of the lateral pallium in birds. J Neurosci 18:5839-5849.

Szele FG, Chesselet MF (1996) Cortical lesions induce an increase in cell number and PSA-NCAM expression in the subventricular zone of adult rats. J Comp Neurol 368:439-454

Takahashi T, Nowakowski RS, Caviness Jr VS (1995) The cell cycle of the pseudostratified ventricular epithelium of the embryonic murine cerebral wall. J Neurosci 15:6046-6057.

van Praag H, Kempermann G, Gage FH (1999) Running increases cell proliferation and neurogenesis in the adult mouse dentate gyrus. Nat Neurosci 2:266-270. 